\title{
Competing by Default: A New Way to Break the Glass Ceiling*
}

\author{
Nisvan Erkal $^{1}$, Lata Gangadharan ${ }^{2}$ and Erte Xiao ${ }^{3}$
}

\begin{abstract}
:
Leadership selection in organizations often requires candidates to actively choose to participate in the competition. We conjecture that such an Opt-in mechanism may contribute to the gender gap observed in leadership positions. We design an Opt-out mechanism where the default is to compete for a leadership position and individuals can opt out of the competition. Data from our experiments show that women are more likely to compete for leadership positions under the Opt-out mechanism and this effectively reduces the gender gap in competition. When given a choice between the Opt-in and Opt-out mechanisms, individuals are equally likely to choose either one. We conclude that the Opt-out mechanism can be an effective and feasible way to break the glass ceiling.
\end{abstract}

Keywords: Glass ceiling; Gender inequality; Competition; Leadership; Defaults; Laboratory experiments

JEL Codes: C92, J16, D01

\footnotetext{
${ }^{1}$ Department of Economics, University of Melbourne, VIC 3010, Australia. Email: n.erkal@unimelb.edu.au

${ }^{2}$ Department of Economics, Monash University, VIC 3800, Australia. Email: lata.gangadharan@monash.edu

${ }^{3}$ Department of Economics, Monash University, VIC 3800, Australia. Email: erte.xiao @ monash.edu
}

\begin{abstract}
* We would like to thank Tim Cason, Daniel Houser, Ragan Petrie, Maria Recalde, Bob Slonim, Tom Wilkening, seminar participants at RMIT, University of New South Wales, George Mason University, Southwestern University of Finance and Economics in China, and participants at the 2016 North American Meetings of the Economic Science Association (ESA), the 11th Annual Australia New Zealand Workshop on Experimental Economics (ANZWEE) and the 2016 Xiamen University International Workshop on Experimental Economics for their comments and feedback. Boon Han Koh has provided excellent research assistance. We also would like to thank the Australian Research Council (DP1094676) for its financial support.
\end{abstract}




\section{Introduction}

Despite the effort and public attention that have been directed toward breaking the glass ceiling, the proportion of women in leadership positions remains disappointingly low. According to Catalyst (2017), although $44.3 \%$ of the labour force in S\&P 500 companies are women, only about $25.1 \%$ of executive/senior-level managers are female. At the CEO level, this proportion is even lower, being only 5.8\%. A similar picture prevails in the political domain and academia (UN Women, 2016; Leslie et al., 2015; Dunn et al., 2014).

Organizations face increasing pressure to adopt diversity programs aimed at encouraging more women to participate in leadership positions. Yet, there is no clear evidence that these diversity programs lead to any significant changes (Dobbin and Kalev, 2016). Numerous training programs have been implemented to promote women to take leadership positions. The evidence for the effectiveness of these training programs, however, is mixed (Bohnet, 2016). There is also an ongoing debate as to whether more intrusive mechanisms such as quotas should be enforced in organizations. The research on quotas has shown mixed evidence on their impact. ${ }^{1}$ Quotas also receive little support from organisations in practice.

It thus remains a challenge to promote women to leadership positions. It may not be enough to alleviate the performance gaps and institutional biases that may affect the hiring and promotion processes. For these efforts to be effective, it is important that women need to show willingness to take on leadership roles. In this paper, we ask how we can increase participation by women in competition for leadership positions.

We propose and test the effectiveness of a new way of breaking the glass ceiling: competing by default. We start by drawing attention to the fact that the leadership selection process that is predominantly used in both the public and private sectors is an Opt-in mechanism where potential candidates have to put their hands up and actively choose to participate in the competition for leadership positions. For example, in many universities, "call for nominations" emails are sent out whenever there is a need to select a leader or form a committee. To be considered for the position, one has to notify the authority of his/her interest. Under this mechanism, the default is

\footnotetext{
${ }^{1}$ See Beaman et al., 2012; Ahern and Dittmar, 2012; Matsa and Miller, 2013; Gangadharan et al, 2016; Afridi et al., forthcoming.
} 
that an individual is not in the competition for the leadership position. ${ }^{2}$ The ubiquity of the Opt-in mechanism is supported by a survey we conducted in 2016 with MBA students at Monash University who have work experience. More than $70 \%$ of the participants indicated that the leadership selection process in their organization is similar to an Opt-in mechanism.

An alternative to the Opt-in mechanism is an Opt-out mechanism where the default has all qualified individuals compete for the leadership positions. In the example above, any qualified staff (e.g., all full professors who have a certain number of years of experience at the institution) will automatically be considered for the open leadership position, but anyone who is not interested in participating can email to opt out.

Changing the default option has been used as a powerful policy instrument and research has shown that it can have a significant impact on important individual decisions such as organ donation, savings and insurance (Madrian and Shea, 2001; Johnson and Goldstein, 2003; Thaler and Benartzi, 2004). Taking these insights from previous research to the leadership selection context, we hypothesize that, compared to the Opt-in mechanism, the Opt-out leadership selection mechanism will encourage more people to participate, and more importantly, mitigate the gender gap in leadership competition. This is because men and women's responses to the change in the default option in the context of leadership selection may vary in magnitude. ${ }^{3}$ For example, if people infer the norm from the default option (Johnson and Goldstein, 2003), the default of participation in leadership selection under the Opt-out mechanism can help break the existing norm or stereotype of male leadership (Koenig et al., 2011). In contrast, the Opt-in mechanism does not challenge such a norm. As a result, the Optout mechanism may have a greater impact on women than men.

To test our hypothesis, we design a controlled laboratory experiment where participants decide whether to compete for a leadership position. Under the Opt-in mechanism, participants cannot compete for the leadership position unless they choose to enter the competition. Under the Opt-out mechanism, participants are in the competition by default unless they explicitly choose not to participate. We consider three different leadership scenarios (Leader, Group and Third-party) with different

\footnotetext{
${ }^{2}$ A default is the option one receives if he/she does not explicitly specify otherwise (Brown and Krishna 2004).

${ }^{3}$ In a different context, Duncan and Li (2016) find that women are more likely to conform to the default in a lying game.
} 
monetary and non-monetary motivations in order to identify the scenarios where a gender gap exists. The role of the leader is to make non-binding suggestions about effort to his/her group prior to a real-effort task. In the Leader scenario, the earnings from this task go to the leader only. In the Group scenario, the earnings are equally divided between the leader and his/her group members. In the Third-party scenario, all of the earnings are transferred to a charity.

We find that under the Opt-in mechanism, women are significantly less likely to participate in the competition for leadership than men in the Third-party scenario, where there is no monetary reward to be the leader. Such a gender gap does not exist under the Leader or Group scenarios. In comparison with the Opt-in mechanism, the Opt-out mechanism effectively reduces the gender gap in competition for leadership positions observed under the Third-party scenario.

We conduct a second study to provide insights on the feasibility of implementing the Opt-out mechanism. This second study has two parts. Part 1 explores whether people are willing to work in organizations that use the Opt-out mechanism by allowing the participants to choose between the two mechanisms. The participants know that their choice can determine which mechanism will be implemented in their group. Our goal is to shed light on whether the Opt-in mechanism is currently more common because people do not like the alternative Opt-out system. We find no evidence suggesting a strong preference for one mechanism over the other.

Part 2 of the second study provides additional insights on people's perceptions of the two mechanisms. Using an incentivized approach, we code and categorize the participants' explanations for their choices between the Opt-in and Opt-out mechanisms. The results offer guidance on the design and implementation of the Optout mechanism.

In addition to the literature on default options, our study is also related to the literature on gender differences in willingness to compete. In this literature, the choice of competition is examined under an Opt-in mechanism, where in order to participate in competition, subjects have to actively choose to do so. This research shows that women are less likely to enter the competition than men (see, e.g., Niederle and Vesterlund, 2007; Balafoutas and Sutter, 2012; Buser et al., 2014; Flory et al., 2015). ${ }^{4}$

\footnotetext{
${ }^{4}$ Gender differences in competitiveness have also been analysed by asking whether performance varies by gender when individuals are forced to compete (i.e., cannot opt out of competition). See, e.g., Gneezy et al. (2003) and Gneezy and Rustichini (2004).
} 
In contrast, we examine an environment where everyone is by default in the competition, but they can make the active choice to opt out of the competition.

The paper is organized as follows. Section 2 describes the experiment design of the first study. The results are reported in Section 3. In Section 4, we report the findings of the second study. Section 5 concludes by discussing the policy implications of our findings.

\section{Experiment Design}

The design consists of two parts, referred to as Experiment I and Experiment II in the instructions. Experiment I was designed to set the stage for the leadership selection that took place in Experiment II. Experiment I was the same across all the treatments while Experiment II varied based on the treatment conditions. Subjects were given instructions for Experiment II only after finishing Experiment I. They were told that one of the two experiments would be randomly chosen for payment. Earnings were revealed at the end of each session. All of these procedures were common knowledge. Figure 1 outlines the timeline of the experiment.

\subsection{Experiment I}

In Experiment I, each subject was given 10 minutes to work on two real-effort tasks: the slider task (Gill and Prowse, 2012) and the encryption task (Erkal et al., 2011). Figures 1 and 2 in Appendix A show the screenshots of the two tasks. The tasks appeared in an alternating fashion on the screen. All participants were given the two tasks in the same order. Subjects earned $\$ 0.25$ for each correctly completed slider task and $\$ 0.50$ for each correctly completed encryption task. The different piece rates were determined in view of the differences in the time needed to complete each task, as observed in our pilots. We included two tasks in Experiment I to minimize potential gender differences in performance. This helps reduce the possibility that any gender difference observed in the competition decisions are due to the gender-biased task used in the experiment. At the end of Experiment I, participants were asked to report in which quantile (of all participants) they think their performance lies (with 1=top 25\% and 4=bottom 25\%). These data on beliefs allow us to examine whether participants' competition decisions in Experiment II are correlated with their beliefs about their performance. 


\subsection{Experiment II}

Experiment II started after Experiment I and had two stages. In Stage 1, subjects were randomly assigned to groups of four and asked to decide whether they would like to participate in the competition for the leadership position. For each group, one leader was selected from those who chose to compete. Our main treatment variable is whether, by default, each participant is in the competition for leadership (the Opt-out mechanism) or not (the Opt-in mechanism). We explain how we implemented these two mechanisms in more detail below. In both treatment conditions, the final selection was always based on the competing subjects' performance in Experiment I, which ensures that the leadership selection is merit-based regardless of the mechanism.

To allow us to obtain a rich set of decision data, we used the strategy method in eliciting the subjects' decisions to compete conditional on rank. Specifically, after the participants were asked to decide whether to compete, they were presented with the four possible ranks they could have obtained in Experiment 1 in a random order. They were then asked to make a competition decision under each possible scenario. ${ }^{5}$ The decision for each rank scenario was taken as final. The computer implemented the decision of each participant under the scenario that matched his/her actual performance rank and selected the leader accordingly. For example, suppose one participant's decision was to compete when s/he was told that his/her performance ranked $1^{\text {st }}$ or $2^{\text {nd }}$, but not to compete otherwise. If his/her actual rank was $3^{\text {rd }}$, the computer would take his/her decision as not to compete.

This approach allows us to reduce the impact of potential gender differences in confidence levels on competition decisions. In addition, it allows us to examine whether differences in performance rank can explain observed gender gaps and whether there is a relationship between rank and the impact of the Opt-out mechanism.

In Stage 2 of Experiment II, subjects were given the opportunity to work on a real-effort task in which they were required to count numbers. We used a different task to the one in Experiment 1 to minimize any potential impact participants' experience in Stage 1 could have on their decisions in Stage 2. Subjects earned a fixed amount of \$20 as long as they finished 20 tasks successfully. After that, each participant could

\footnotetext{
${ }^{5}$ While making the first unconditional competition decision, participants did not know that they would also be asked to make the competition decision conditional on rank.
} 
continue to work on additional tasks up to a maximum of 40 tasks if s/he wanted. Each additional task completed generated $\$ 0.25$.

The leader's role in our experiment was to make a suggestion on how many additional tasks the group members should complete. ${ }^{6}$ Using the strategy method, we obtained data from both the leaders and non-leaders, regardless of their decision to compete. Specifically, at the beginning of Stage 2, each participant was asked to decide how many tasks he/she would suggest other members of the group to complete if s/he were selected to be the leader. ${ }^{7}$ Subjects were told that if they are selected to be the leader, then the following message would be sent to their group members: "Please complete at least more tables after you finish your own 20 tables."8 ${ }^{8}$ The leader's suggestion was non-binding in that everyone could still work as much or as little as he/she wished. Once the participants made their suggestion decisions, they were informed if they were selected to be the leader.

After receiving the leader's suggestion and completing 20 tables successfully, participants were asked to state how many additional tables they would like to work on. The initial 20 tables that the participants completed allowed them to make this decision after learning the nature and difficulty of the task. It also allowed us to reduce the impact of other motivations for exerting effort (such as curiosity about the task, experimental demand effect, etc.). At any time, subjects could stop working on the task and choose to browse the Internet while waiting for the other participants to finish their activities.

\section{Opt-out vs. Opt-in Mechanism}

The leadership selection mechanism was explained to the subjects in Stage 1 of Experiment II. Under the Opt-out mechanism, subjects were told that the computer would select the highest performer in Experiment I among the four group members. However, one could indicate his/her desire not to compete. The computer would then select among the remaining competitors. If everyone opted out, the computer would randomly select one group member to be the leader. Thus, under the Opt-out

\footnotetext{
${ }^{6}$ Levy et al. (2011), Feltovich and Grossman (2012), and Brandts et al. (2014) contain designs with a similar concept of leadership.

${ }^{7}$ Note that it is valid to ask this question even of those who decided not to compete as they may still be selected as the leader if no one in the group chooses to participate in the leadership competition.

${ }^{8}$ We did not allow free-form messages because participants' decisions to compete to be the leader might then depend on their beliefs regarding the quality of the messages they can provide. Our goal was to minimize the possibility of confounding effects that may arise from qualitative differences in messages.
} 
mechanism, the default was that everyone would participate in the competition, but one could always choose not to compete if he/she wished to.

The Opt-in mechanism was designed to be identical to the Opt-out except that the default was that one would not be in the competition unless one actively chose to compete. Specifically, subjects were told that the computer would randomly select one of the four group members to be the leader. However, one could indicate his/her desire to compete. The computer would then select the highest performer among the competitors (i.e., those who expressed an interest to compete). Importantly, both mechanisms use the same selection criteria and select a leader based on performance.

Figure 3 in Appendix A shows the decision screens that the subjects saw in the two treatments. In the Opt-out treatments, the option "I want to compete for the leader position” was pre-selected as the default. To opt out of the competition, subjects needed to check the other option "I do NOT want to compete for the leader position" before clicking the "CONTINUE" button. In contrast, in the Opt-in treatments, the option "I do NOT want to compete for the leader position.” was pre-selected. To compete, subjects needed to check the option "I want to compete for the leader position" before clicking the "CONTINUE" button. In both treatments, the decisions to compete were privately made and not shared with anyone else in the experiment.

\section{Leadership Scenarios}

Our experimental design is guided by a conceptual framework that assumes leadership decisions are potentially shaped by not only monetary incentives, but also nonmonetary incentives such as altruism (see, e.g., Madsen, 2008) and personal satisfaction obtained from being in a leadership role or having decision rights (see, e.g., Bartling et al, 2014). Different leadership positions incentivize leaders in different ways. For example, in some positions, there may be a larger scope to earn monetary rewards while in others, there may be a larger scope to help others in society. We conjecture that the presence of a gender gap may depend on the incentive structures underlying the different leadership positions.

As a result, we consider three leadership scenarios where leaders are potentially motivated by different (monetary and non-monetary) considerations. We refer to the leadership scenarios based on who receives the profits generated by the additional tasks completed by the group in Stage 2 of Experiment II. In the Leader scenario, the profit from the additional tasks go to the leader only. That is, the other three group members 
do not benefit from the additional tasks completed either by themselves or by others. In the Group scenario, the profit is equally split among the four group members. That is, the leader and each of the non-leaders earn one-fourth of the total profit created. In the Third-party scenario, all the profits are transferred to a charity. Neither the leader nor the non-leaders benefit from the additional tasks. The subjects are told that the profits would go to one of the five charities mentioned in the instructions (see Appendix A). The computer randomly chooses one of these charities. Subjects receive a copy of the receipt as confirmation of their group's donation.

In Section 3, we discuss our hypotheses regarding the gender gap in the three scenarios. Our goal is to focus on those leadership scenarios where the gender gap appears under the Opt-in mechanism and examine whether the Opt-out mechanism mitigates the gender gap. Since we compare the Opt-out and Opt-in mechanisms under the three different leadership scenarios, the experiment has a 2x3 design and consists of six treatments in total. Table 1 summarizes the treatment design.

\subsection{Experimental Procedure}

The experiment was conducted at the Experimental Economics Laboratory at the University of Melbourne ( $\left.E^{2} \mathrm{MU}\right)$ and programmed using z-Tree (Fischbacher, 2007). Subjects were recruited using ORSEE (Greiner, 2015) and consisted of students from different academic disciplines across the campus. A total of 496 subjects participated in the experiment and each subject could participate in only one of the six treatments. In each treatment, we collected data from approximately 80 participants with roughly half female and half male (see Table 1 ). ${ }^{9}$ There were a total of four sessions per treatment. Each session lasted about one and a half hours. Participants earned on average \$38, including a show-up fee of $\$ 10$.

A survey was conducted at the end of the experiment. In the survey, in addition to demographic questions, we included six questions that measure social value orientation (henceforth, SVO, Murphy et al., 2011). The SVO measure is a simple way of eliciting social preferences and allows us to examine whether the observed gender differences in leadership decisions are correlated with the subjects’ pro-sociality. ${ }^{10}$

\footnotetext{
${ }^{9}$ Two participants left early without completing all the decisions. We thus drop their data from the analysis.

${ }^{10}$ SVO is measured using the six primary SVO slider terms provided in Murphy et al. (2011). Types are classified based on the resulting SVO slider angles. An angle greater than 57.15 degrees is classified as an altruistic type, an angle between 22.45 and 57.15 degrees is classified as a prosocial type, an angle
} 
Subjects are randomly paired with someone else in the room and make a series of resource allocation decisions. To incentivize the decisions, one of the six questions was randomly selected for payment. For this question, the computer randomly picked one participant in each pair and implemented their allocation decision.

\section{Hypotheses}

In this section, we present a simple framework to illustrate our hypotheses as to why the Opt-out mechanism may diminish the gender gap. We start by discussing why, with the conventional Opt-in mechanism, the gender gap may be different under the different leadership scenarios introduced in Section 2.2.

\section{Decision to compete for the leadership position}

Let $L_{i}^{S}$ stand for the payoff that subject $i$ expects to receive if s/he becomes the leader. The superscript $S \in\{L, G, T\}$ denotes the leadership scenario (Leader, Group, and Third-party). We assume that both monetary and non-monetary factors (such as personal satisfaction and altruism) contribute to $L_{i}^{S}$.

Let $E_{i, L}^{S}$ and $E_{i, F}^{S}$ stand for the (expected) monetary income that subject $i$ would earn in the role of a leader and a follower in Stage 2, respectively. Monetary incentives for leadership originate from any additional compensation that the subject would receive as a leader as opposed to a follower. All subjects earn a fixed amount of \$20 as long as they finish the first 20 tasks successfully. Earnings beyond this are dictated by who receives the profits from the extra tasks completed. In the Leader scenario, since the leader earns all the income from the additional tasks completed by the group, we have $E_{i, L}^{L} \geq E_{i, F}^{L}$, which holds as an equality in the unlikely case where the group members choose not to complete any additional tasks. In the Third-party scenario, all the income goes to a charity and $E_{i, L}^{T}=E_{i, F}^{T}$. In the Group scenario, the group members share equally the earnings from the extra tasks completed. Thus, $E_{i, L}^{G}=E_{i, F}^{G} \cdot{ }^{11}$

\footnotetext{
between -12.04 and 22.45 degrees is classified as an individualistic type, and an angle less than -12.04 degrees is classified as a competitive type.

${ }^{11}$ It is possible to have $E_{i, L}^{G}>E_{i, F}^{G}$ if a participant believes that under his/her leadership, the group will complete more tasks. This would require the participant to expect his/her influence as the leader to be more than an average person's influence. Since this possibility does not have a significant impact on our main hypotheses, we assume that $E_{i, L}^{G}=E_{i, F}^{G}$ for simplicity.
} 
Let $P_{i}^{S}$ stand for the personal satisfaction that subject $i$ receives from being a leader under scenario $\mathrm{S}$. This is the satisfaction that an individual may receive from having the "leader" title or the power to influence others' decisions. Note that for some subjects, $P_{i}^{S}$ may be negative if, for example, they do not like to suggest to others what to do or if they think they are violating a social norm by being in a leadership position.

Finally, both leaders and followers may have different opportunities to help others in Stage 2. We use $G_{i}^{S}$ to denote the utility that subject $i$ receives from helping others. Under the Leader scenario, only the followers would, potentially, be getting utility from helping others since all of the profits from the additional tasks completed by the group members go to the leader. Hence, $G_{i, F}^{L} \geq G_{i, L}^{L}=0 .{ }^{12}$ Under the Group and Third-party scenarios, both the leader and the followers can help others. For simplicity, we assume that $G_{i, L}^{G}=G_{i, F}^{G}$ and $G_{i, L}^{T}=G_{i, F}^{T}$ although, as mentioned above (footnote 10), it is possible that one may expect a different number of tasks to be completed by the group if $s / h e$ is the leader than if someone else is the leader.

In summary, assuming an additively separable utility function, the following expression represents the payoff that subject $i$ would receive from being the leader:

$$
L_{i}^{S}=E_{i, L}^{S}+P_{i}^{S}+G_{i, L}^{S}
$$

In our experiment, to become the leader, one has to choose to compete and win the competition. Let $\rho_{i}$ stand for subject $i$ 's subjective probability of winning in the competition for leadership. ${ }^{13}$ Then, subject $i$ 's expected payoff from participating in the competition is

$$
\rho_{i}\left(E_{i, L}^{S}+P_{i}^{S}+G_{i, L}^{S}\right)+\left(1-\rho_{i}\right)\left(E_{i, F}^{S}+G_{i, F}^{S}\right)+C_{i},
$$

where $C_{i}$ represents the utility or disutility that the subject receives from competing. ${ }^{14}$ Its value will be positive for those subjects who are competitive and who like

\footnotetext{
12 Note that $G_{i, F}^{L}$ is not likely to be high because the followers would be helping the leader who is already earning more than them.

${ }^{13}$ By using the strategy method, we collect data on subjects' willingness to compete conditional on the rank information that we provide to them. Hence, when they are asked to assume that their rank in Experiment I is $1^{\text {st }}$, they know that their probability of winning, if they choose to participate, is one. If their rank is not $1^{\text {st }}$, then $\rho_{i}$ is determined by subject $i$ 's beliefs about others' participation decisions. It would depend on subject $i$ 's beliefs about the distribution of types in society (i.e., the distribution of $P_{i}^{S}$, etc.).

${ }^{14}$ There are different ways to represent the impact of competition on the utility of individuals. We use $C_{i}$ to denote the utility or disutility individuals receive from being in a competitive environment. It is different from the joy of winning in that it is independent of the outcome of the competition.
} 
competitive environments, and negative for those subjects who are averse to competition.

While deciding whether to enter the competition for leadership, subject $i$ compares this expected payoff with the payoff from not participating, $E_{i, F}^{S}+G_{i, F}^{S}$, since s/he will be a follower in that case. Thus, s/he will compete if:

$$
\rho_{i}\left[\left(E_{i, L}^{S}-E_{i, F}^{S}\right)+P_{i}^{S}+\left(G_{i, L}^{S}-G_{i, F}^{S}\right)\right]+C_{i}>0
$$

Based on the assumptions made above, this condition reduces to the following under the Leader, Group and Third-party scenarios, respectively:

$$
\begin{gathered}
\rho_{i}\left[\left(E_{i, L}^{L}-E_{i, F}^{L}\right)+P_{i}^{L}-G_{i, F}^{L}\right]+C_{i}>0 \\
\rho_{i} P_{i}^{G}+C_{i}>0 \\
\rho_{i} P_{i}^{T}+C_{i}>0
\end{gathered}
$$

This simple framework shows that gender gaps may emerge in the competition for leadership due to potential differences in mainly $P_{i}^{S}, C_{i}$, and $\rho_{i}$. For example, previous research on the stereotype of male leadership (Koenig et al., 2011) suggests that while men may derive personal satisfaction from being in leadership positions $\left(P_{i}^{S}>0\right)$, women do not or may even be averse to being leaders $\left(P_{i}^{S} \leq 0\right)$. There is also evidence suggesting that men enjoy competition $\left(C_{i}>0\right)$ and women shy away from it $\left(C_{i} \leq 0\right)$ (see, e.g., Niederle and Vesterlund, 2007).

Our framework also shows that monetary incentives may influence the decision to enter the competition for leadership under the Leader scenario. Previous studies have shown that although women are less willing to compete than men (under the Opt-in mechanism), the gender gap gets smaller as the size of the reward to competition is increased (Goldin and Rouse, 2000; Mulligan and Rubinstein, 2008; Flory et al., 2015; Petrie and Segal, 2015). This is consistent with our framework. Although there may be differences between men and women in the magnitudes of $P_{i}^{S}, C_{i}$ and $\rho_{i}$, when monetary incentives are sufficiently strong, such differences are less likely to play a critical role. This implies that, when monetary incentives are sufficiently strong, a gender gap is less likely to be seen under the Leader scenario. Note that monetary incentives have no impact on the participation decisions under the other scenarios.

\section{Opt-out vs. Opt-in mechanism}

Recent research has shown that defaults can have a significant impact on important individual decisions, such as organ donation, savings, and insurance (Madrian and 
Shea, 2001; Johnson and Goldstein, 2003; Thaler and Benartzi, 2004; Li et al., 2013). There are several explanations for the default effect (Smith et al., 2013). For example, the default may be viewed as the norm or the recommendation of the policy makers (e.g., in the case of saving behavior, that one should increase savings for retirement). People tend to conform to the norm or follow the recommendation if they trust the policy makers (McKenzie et al., 2006). Or, defaults may affect the meaning attached to the participation choice. For example, Davidai et al. (2012) show that choosing not to donate an organ under an opt-out policy is perceived as morally more deficient than the same choice under an opt-in policy. ${ }^{15}$

These findings on the default effect imply that it is reasonable to expect more participants (both men and women) to choose to compete for leadership positions under the Opt-out mechanism than under the Opt-in mechanism. Based on the simple framework above, for example, some individuals may have a negative $C_{i}$ value under the Opt-in mechanism if they do not like to raise their hands and assert themselves, or if they think that by participating in the competition, they will be going against the norm implied by the default under the Opt-in mechanism. Hence, they may not participate in the competition for leadership under the Opt-in mechanism, but they may choose to participate under the Opt-out mechanism.

The novel hypothesis that we test in this paper is that any gender gap we may observe under the Opt-in mechanism can be reduced under the Opt-out mechanism. Putting their hands up for participation in competition under the conventional Opt-in mechanism may be especially difficult for women since they are often brought up not to assert themselves (Ruble, Martin, and Berenbaum 2006). In addition, making the decision to compete may signal competitiveness or even aggressiveness. Since such an image of competitiveness can be harmful for women, it can discourage them from participating in the competition. This is consistent with studies which have shown that behaving in a more masculine and self-promoting manner does not appear to help women reach leadership positions and may even backfire (Bowles et al., 2007; Brescoll, 2011). This can be one reason why women are more likely to have $C_{i}<0$ under the Opt-in mechanism. In contrast, choosing to compete for leadership under the Opt-out

\footnotetext{
${ }^{15}$ It has also been argued that taking the default option can help save on the cognitive effort of making decisions, especially when one is conflicted (Gigerenzer, 2008).
} 
mechanism does not necessarily convey the same image of competitiveness or aggressiveness since one does not need to actively choose to compete.

A second possible reason why a change in the default may decrease the gender gap in leadership competition is related to the personal satisfaction parameter, $P_{i}^{S} \cdot{ }^{16}$ As stated above, a gender gap in leadership competition decisions may arise when, for example, men have $P_{i}^{S}>0$, but women have $P_{i}^{S}<0$. One reason why women may have $P_{i}^{S}<0$ is that, under the Opt-in mechanism, they feel that by being the leader, they are going against the existing norm of male leadership (Koenig et al., 2011). The default of participating in leadership selection (the Opt-out mechanism) can break the existing stereotype of male leadership and may make being in a leadership position look more acceptable. In this way, the Opt-out mechanism can reduce the gender difference in $P_{i}^{S}$.

In sum, under the Opt-in mechanism, we hypothesize that we are less likely to see a gender gap under the Leader scenario than under the other two leadership scenarios. Moreover, we conjecture that the Opt-out mechanism can mitigate the potential gender gap in participation in the leadership competition observed under the conventional Opt-in mechanism.

\section{Results}

\subsection{Leadership Competition Decisions}

Figure 2 (a) shows the proportion of participants who decide to compete in each of the six treatments. These decisions are not conditional on rank. First, we note that in the Leader scenarios, almost all of the participants (more than 97\%) decide to compete under both the Opt-in and the Opt-out mechanisms. This is not surprising given the high monetary incentives for being the leader in this scenario. In contrast, the proportion of participants who compete is lower in the Group and the Third-party scenarios (79\% and 65\%, respectively). Consistent with previous findings on the default effect, the Opt-out mechanism significantly increases participation in

\footnotetext{
${ }^{16}$ There may be several channels through which a change in the default mechanism may decrease the gender gap in leadership competition. We focus on $P_{i}^{S}$ and $C_{i}$ here since differences in these two parameters would result in a gender gap even when $\rho_{i}=1$, which would be the case when the subject makes his/her decision conditional on being ranked $1^{\text {st }}$. Hence, if the subject participates in this case, $\mathrm{s} / \mathrm{he}$ does not need to form expectations on the likelihood of winning the competition. S/he knows with certainty that s/he will win.
} 
competition in these two scenarios (95\% vs. $79 \%$, $90 \%$ vs. $65 \%$, using a difference in proportions Z-test, $\mathrm{p}<0.01$ ).

Our main interest is the gender differences in competition participation rates. Figure 2(b) reports the participation rates by gender in each treatment. Under the Optin mechanism, we observe no gender gap in the Leader scenario and Group scenarios. The gender gap in competition is, however, significant in the Third-party scenario where there is no monetary reward to be the leader ( $79 \%$ for the men vs. $50 \%$ for the women, Z-test, $\mathrm{p}<0.01)$. Supporting our hypothesis, when the Opt-out mechanism is applied to leadership selection in the Third-party scenario, the gender gap is much smaller and no longer significant, although men are still slightly more likely to compete than women ( $95 \%$ vs. $85 \%$, Z-test, $\mathrm{p}=0.13$ ).

The results under the Opt-in mechanism for the Leader and Third-party scenarios are consistent with previous findings which show that women are less willing to compete than men when the monetary rewards from competition are relatively low. It is interesting that we do not observe a gender gap in the Group scenario. Based on the framework in Section 3, one possible explanation is that women find leadership more enjoyable under the Group scenario than under the Third-party scenario. This may be the case if, for example, asking the group to work for a third party feels like a more substantial request which women find less enjoyable to do. ${ }^{17}$

We next explore gender differences using a regression framework. We estimated ordinary least squares regressions with clustered standard errors at the session level, controlling for subject characteristics, such as SVO and expectation of one's rank in Experiment $1{ }^{18}$ Table 2 presents the results for the three scenarios in Panels A, B and C. In each panel, the first column (Regression 1) reports results without controlling for subject characteristics. The second column (Regression 2) reports results after controlling for SVO and subjects' beliefs about their ranks. As documented above, the Opt-out mechanism leads to a significantly higher participation in the leadership competition in the Group and Third-party scenarios. Moreover, the gender gap only appears in the Third-party scenario. The main variable of interest in the regressions is the interaction term between the mechanism and gender (Opt Out*Female). This

\footnotetext{
${ }^{17}$ This conjecture is also consistent with our finding that the suggested number of additional tasks are the highest under the Group scenario.

${ }^{18}$ We report results from linear regressions to make it easier to interpret the coefficients. Probit regressions generate qualitatively similar results although the significance levels vary at the margin.
} 
variable is significant in the Third-party scenario, but not in the others. This confirms that the Opt-out mechanism significantly reduces the gender gap in the Third-party scenario as compared to the Opt-in mechanism by increasing the participation of women in competition.

Regression 2 shows that subjects' SVO scores do not play a role in explaining their competition decisions under any of the leadership scenarios. As predicted by our framework in Section 3, this finding suggests that the role of altruism in leadership competition decisions is limited. The results from Regression 2 also show that belief about one's rank does not affect the decision to participate in competition. ${ }^{19}$ However, this does not necessarily mean that subjects would make the same competition decisions irrespective of their actual rank. We next analyze competition decisions conditional on rank.

\section{Competition decisions conditional on rank}

Figure 3 plots the participants' competition decisions conditional on rank. Since we observe the gender gap only in the Third-party scenario, we focus on these data only. The data show that under the Opt-in mechanism, the gender gap remains large across the four ranks (Z-tests, p-values $<0.05$ except for the scenario where participants are ranked as the $3^{\text {rd }}$ ). In contrast, the gender gap is small and not significant under the Optout mechanism in all four ranks (Z-tests, p-values $>0.20$ ). In particular, in the cases where the participants' rank is in the top two, women are as likely to compete as men under the Opt-out mechanism ( $1^{\text {st }}$ rank: 93\% vs. 93\%; $2^{\text {nd }}$ rank: 86\% vs. 83\%).

It is striking that under the Opt-in mechanism, even when the female participant is ranked $1^{\text {st }}$ and therefore can definitely win the competition, only $60 \%$ of women are willing to compete for leadership. This result is consistent with the framework presented in Section 3 and implies that, with the conventional Opt-in mechanism, the gender gap will persist even when women are top performers. This is no longer the case, however, with the Opt-out mechanism. With the Opt-out mechanism, the gender gap disappears when women are high-ranked performers.

Table 3 reports results from multivariate regression analysis that examine this further. In all the regressions, the standard errors are clustered at the session level. The

\footnotetext{
${ }^{19}$ Belief about one's rank remains insignificant when we replace the belief variable in Regression 2 with dummies for each of the possible ranks.
} 
competition decisions for the $1^{\text {st }}$ and $2^{\text {nd }}$ ranks are not significantly different from each other and the same is true for the bottom two ranks (Z-tests, $\mathrm{p}>0.15$ ). Therefore, for each subject, we take the average of the competition decisions over the first two ranks and the bottom two ranks. Panel A reports the regression results for these two ranks separately. ${ }^{20}$ We focus on the decisions made by the subjects in the top two ranks as these are the ranks from which the leaders are most likely to be selected. As Table 3 shows, for the competition decisions made by individuals ranked in the top, the interaction between gender and the Opt-out mechanism is positive and statistically significant. This is similar to the finding from Table 2, which is unconditional on rank. When ranked in the bottom two positions, the Opt-out mechanism still has a significant positive impact on the willingness to compete, although subjects in this case are unlikely to be selected and it is therefore unlikely to affect the leadership selection outcome. The coefficient of the interaction in this case is also positive but not significant.

Panel B of Table 3 reports difference-in-difference estimates by pooling the data from the top two and bottom two ranks. This allows us to examine gender differences in the impact of the Opt-out mechanism on competition decisions conditional on rank. The independent variable is whether the subject is ranked in the top two positions (“Top2”). We allow the coefficients of Top2 to be different across gender (women vs. men) and the selection mechanisms (Opt-out vs. Opt-in). Thus, there are four independent variables in total. Since there are two decisions from each participant, we use a random effects error structure to control for individual effects. The regression results show that Top2 has a significant positive effect on the competition decisions of both men and women in both the Opt-in and Opt-out treatments. The coefficient of “Top2*Male*OptIn" $\left(\beta_{4}\right)$ is significantly greater than the coefficient of “Top2*Female*OptIn” $\left(\beta_{3}\right)$ (chi-square test, $\mathrm{p}<0.01$ ). This means that in the Opt-in mechanism, the effect of being in one of the top two positions is greater for men than for women. In contrast, the coefficient of “Top2*Male*OptOut” $\left(\beta_{2}\right)$ is lower than that of “Top2*Female*OptOut” $\left(\beta_{1}\right)$, although the difference is not statistically significant (chi-square test, $\mathrm{p}=0.494)$. The difference-in-difference test $\left(\beta_{2}-\beta_{1}\right.$ vs. $\beta_{4}-\beta_{3}$, chisquare test, $\mathrm{p}=0.01$ ), shows that the gender difference in the effect of Top2 under the

\footnotetext{
${ }^{20}$ The main results are similar when we analyse the results separately in terms of the first and second rank.
} 
Opt-in mechanism is significantly larger than under the Opt-out mechanism. These results suggest that under the traditional Opt-in mechanism, the improvement in rankings (and therefore the chance of winning) has a more significant effect on men's willingness to compete for leadership positions than women's. With the Opt-out mechanism, the gender difference disappears.

In summary, the data from both the unconditional and conditional competition decisions support our hypothesis that the Opt-out mechanism can effectively reduce the gender gap in participation in competition for leadership positions. When considering a new mechanism that promotes gender equality in leadership, it is also important to assess whether and how the new mechanism may affect team performance. In organizations, diversity in leadership may matter for many different reasons and may affect team performance in many different ways. We next explore this question in a limited way within the bounds of our experimental design by examining the quality of the chosen leader, the number of suggested tasks, and the number of completed tasks under the two mechanisms. Since a gender gap only appears in the Third-party scenario, we focus on this scenario in the main text and report on the other two leadership scenarios in Appendix D.

\subsection{Team Performance Outcomes in Third-party scenarios}

17 out of the 21 selected leaders under the Opt-in mechanism and 19 out of the 21 selected leaders under the Opt-out mechanism were the best performers in their group in Experiment 1. This result is not surprising given the pattern of the participation decisions shown in Figure 3. This suggests that adopting the Opt-out mechanism does not compromise the quality of the selected leader as measured by the metric specified in our experiment. In other words, high-performers are not less likely to participate in competition under the Opt-out mechanism.

Table 4 reports the average number of suggested tasks by the selected leaders and the competitors (i.e., those who chose to compete for the leadership position) under the Opt-in and the Opt-out mechanisms. We find no significant difference between the two mechanisms in the number of tasks suggested either by the elected leaders or the competitors. $^{21}$

\footnotetext{
${ }^{21}$ The results are similar when comparing the two mechanisms for male competitors and female competitors separately. On average, the male competitors in the Opt-in mechanism suggest 20 and those in the Opt-out mechanism suggest 21. The female competitors in both the Opt-in and the Opt-out
} 
Table 5 reports the average number of tasks completed under the Opt-out and the Opt-in mechanisms. It shows that the number of completed tasks (both by the leaders and non-leaders) under the two leadership selection mechanisms are very close. We also compare the number of tasks completed when the number suggested by the elected leader is either high or low to examine the effect of the leaders' suggestions on effort. Although participants were allowed to suggest any integer number between 0 and 40 , the majority (more than 50\%) suggested 10, 20, or 40 under both mechanisms. To allow for a sufficient number of observations in each cell, we use 20 as the cutoff and define the number as low when the suggestion is less than 20 and high otherwise. ${ }^{22}$ We find that under both the Opt-in and Opt-out mechanisms, participants completed significantly more tasks when the suggested number is high compared to when it is low (Opt-in: 29.2 vs. 18.1; Opt-out: 29.1 vs. 22.7; Mann Whitney tests, $\mathrm{p}<0.05$ ). Consistent with the previous literature (Levy et al., 2011 and Houser et al., 2014), this result shows that the leader's non-binding suggestion has a significant impact on the team's effort.

To summarize, we find that the Opt-out mechanism can be an effective way to promote more women to participate in the competition for leadership positions without worsening leadership outcomes. Another important consideration in introducing a new mechanism is whether people will accept it. Are women (and men) willing to work in an organization with an Opt-out leadership selection mechanism? The impact of the Opt-out mechanism in the real world critically depends on this. Does the prevalence of the Opt-in mechanism in society imply that there is a strong distaste for the Opt-out mechanism? Could it be the case that the use of an Opt-out mechanism leads people to participate in competition when they really do not want to ${ }^{23}$ To address these concerns, we conduct a second study to examine individuals’ preferences between the Opt-in and Opt-out mechanisms.

\section{Preferences for the Opt-in and Opt-out mechanisms}

\footnotetext{
mechanisms suggest 17. Although the male competitors' suggestion is slightly higher than the females', the difference is not significant (Mann-Whitney test, $\mathrm{p}=0.14$ ).

${ }^{22}$ Using other cutoffs give similar results although the significance levels change. This may be because of the drop in the number of observations in some of the cells. We also ran a regression analysis. The independent variables include the elected leader's suggestion and a dummy for the Opt-in mechanism. The results show that the suggestion has a significant positive impact on the number of completed tasks while the Opt-in dummy variable is not significant.

${ }^{23}$ See Smith et al. (2013) for more discussion on the ethics of defaults.
} 
Building on the first study, the second study consists of two parts. In Part 1, we examine subjects' selection between the two mechanisms when given the choice. In Part 2, we conduct content analysis of subjects' survey answers regarding their choice, which provides additional details on individuals' considerations of the design of leadership selection mechanisms.

The experiment in Part 1 is similar to the first study consisting of both Experiment I and Experiment II except that we add another stage to the beginning of Experiment II. ${ }^{24}$ In this stage, the Opt-in and Opt-out mechanisms are explained to the participants using the description from the first study; these are referred to as Method $\mathrm{X}$ and Method $\mathrm{Y}$ in the instructions. Participants were then asked to decide which mechanism they would like to use in their group, or to indicate indifference. Given that the Opt-out mechanism does not make any difference in the Leader scenario as almost everyone chooses to compete, we considered the Group and the Third-party scenarios only in this second study.

After all of the subjects in the group made their decisions, one subject was randomly selected and his/her decision was implemented for the group. If the selected subject had indicated indifference, the computer randomly selected one of the two mechanisms with equal probability. All the other design details remained the same as in the Group and Third-party scenarios in the first study. We collected data from 164 participants, 80 of which were in the Group scenario and 84 were in the Third-party scenario.

In the Third-party scenario, $40.5 \%$ of the participants chose the Opt-out mechanism, 35.7\% chose the Opt-in mechanism, and 23.8\% chose "Indifferent". A similar pattern is observed in the Group scenario: $47.5 \%$ chose the Opt-out mechanism, $37.5 \%$ chose the Opt-in mechanism, and $15.0 \%$ chose "Indifferent". These data show that the percentage choosing the Opt-out mechanism is slightly higher than the percentage choosing the Opt-in mechanism although the difference is not statistically significant in either leadership scenario (Z-tests, $\mathrm{p}>0.20$ ).

We also examine whether there is a gender difference in these preferences. Figure 4 reports the distribution of the choices by gender and leadership scenario. Although there are some differences in the choices between women and men, none of these differences are statistically significant, except that in the Group scenario, the

\footnotetext{
${ }^{24}$ The instructions can be found in Appendix B.
} 
observed gender difference in the Opt-out mechanism is marginally significant at the 90\% confidence level (with more men preferring this mechanism than women).

In addition to studying the choices between the two mechanisms, it is useful to examine subjects' considerations when deciding on a mechanism. In light of this, subjects were asked at the end of the experiment to explain the reasoning behind their decisions. This information can help us clarify the tradeoffs between the two mechanisms and thus assist institution designers craft more suitable leadership selection mechanisms. For example, if people are likely to view the leader selected under the Opt-out mechanism as less motivated, then it may help to make it clear in the selection criteria that, in addition to high performance skills, candidates must show evidence of high motivation.

In Part 2 of the second study, we conducted incentivized content analysis of the survey responses to shed light on this. We applied the method introduced in Houser and Xiao (2011). Specifically, we first read the open-ended responses with two research assistants who were blind to the research questions relating to our project. Together we came up with seven categories, including fairness, freedom to choose, leader quality, and desire to increase own chance of being selected, to evaluate the subjects' responses. A complete list of the categories used can be found in the instructions provided in Appendix C. We then recruited 29 subjects to code the responses using the categories determined. The coding was incentivized in the following way. At the end of each coding session, three responses were randomly picked for payment. For each of the three responses, if a coder's chosen category matched the most commonly chosen one by the rest of the coders in the session, he/she was paid $\$ 5$.

The analysis suggests that across the two scenarios where we observe the Optout mechanism effect (Group and Third-party), the Opt-out mechanism is not perceived as inferior to the Opt-in mechanism by those subjects who value fairness and those who would like to maximize their chance of winning. It is viewed as the better option for ensuring quality of leadership. The Opt-out mechanism may be less preferred by those who care about freedom of choice although less than $10 \%$ of subjects see this as an important factor. Further details of our analysis can be found in Appendix E.

\section{Conclusion}

The proportion of women in leadership positions remains disappointingly low. As a result, promoting gender diversity in leadership positions remains a major challenge for 
public and private sector institutions across the world. A precondition for gender equality in leadership positions is to promote equal participation in the competition for leadership selection. This paper investigates how the leadership selection mechanism can be changed to increase the number of women who compete for leadership positions. We propose and show that, compared with the traditional Opt-in mechanism, using an Opt-out mechanism in leadership selection leads more women to compete for leadership positions.

Importantly, our paper shows that even in those institutions where there are no biased attitudes towards the advancement of women and where there are no performance gaps between women and men, we may still observe gender gaps in leadership positions if the leadership selection mechanism is configured such that more men than women are participating in the competition for leadership. As a result, our findings imply that encouraging more participation in competition by women through the use of an appropriate selection mechanism can be a necessary complement to the diversity policies and training programs adopted to overcome biases and close performance gaps.

In our follow-up study, we show that when given a choice, individuals do not have a bias against the use of an Opt-out mechanism. This result provides supporting evidence for the practicability of the Opt-out mechanism. However, it is important to note that our study explores the impact of an Opt-out mechanism on participation within the bounds of a well-defined laboratory experiment. Implementation of an Opt-out mechanism in the real world may require other adjustments to an institution's culture. For example, the results from our follow-up study suggest that, in a culture where freedom of choice is highly valued, care must be taken to make sure that people do not see the Opt-out mechanism as reducing their freedom of choice.

In light of our findings, exploring the suitability and potential of the Opt-out mechanism in the field is an important avenue for future work. In the field, additional issues may need to be considered while determining the effectiveness of the Opt-out mechanism. For example, on the one hand, especially when the population of qualified candidates is large, transaction costs may be higher with an Opt-out mechanism since more people participate in competition for leadership positions. This implies that the selection process may take longer and, for certain type of positions, organizations may be less willing to adopt this mechanism. On the other hand, the Opt-out mechanism may have an even stronger impact in the field since under this mechanism, employees 
would be able to avoid the stress associated with the need to negotiate in order to put themselves forth as a candidate under an Opt-in mechanism. 


\section{References}

Afridi, F., Iversen, V. and Sharan, M.R. Forthcoming. "Women Political Leaders, Corruption and Learning: Evidence from a Large Public Program in India”, Economic Development and Cultural Change.

Balafoutas, L. and Sutter, M. 2012. “Affirmative Action Policies Promote Women and Do Not Harm Efficiency in the Lab”, Science, 335 (6068), 579-582.

Bartling, B., Fehr, E. and Herz, H. 2014. "The Intrinsic Value of Decision Rights”, Econometrica, 82 (6), 2005-2039.

Beaman, L., Duflo, E., Pande, R. and Topalova, P. 2012. "Female Leadership Raises Aspirations and Educational Attainment for Girls: A Policy Experiment in India”, Science, 335 (6068), 582-586.

Bohnet, I. 2016. What Works: Gender Equality by Design, Cambridge: Harvard University Press.

Bowles, H.R., Babcock, L. and Lai, L. 2007. “Social Incentives for Gender Differences in the Propensity to Initiate Negotiations: Sometimes It Does Hurt to Ask", Organizational Behavior and Human Decision Processes, 103 (1), 84-103.

Brandts, J., Cooper, D. J. and Weber, R. A. 2014. "Legitimacy, Communication, and Leadership in the Turnaround Game”, Management Science, 61 (11), 2627-2645. Brescoll, V. 2011. "Who Takes the Floor and Why: Gender, Power, and Volubility in Organizations”, Administrative Science Quarterly, 56 (4), 622-641.

Brown, C. and Krishna, A. 2004. "The Skeptical Shopper: A Metacognitive Account for the Effects of Default Options on Choice”, Journal of Consumer Research, 31 (3), 529-539.

Buser, T., Niederle, M. and Oosterbeek, H. 2014. “Gender, Competitiveness, and Career Choices”, Quarterly Journal of Economics, 129 (3), 1409-1447.

Catalyst. 2017. Pyramid: Women in S\&P 500 Companies, New York: Catalyst.

Cohen, J. 1960. “A Coefficient of Agreement for Nominal Scales”, Educational and Psychological Measurement, 20 (1), 37-46.

Croson, R. and Gneezy, U. 2009. “Gender Differences in Preferences”, Journal of Economic Literature, 47 (2), 448-474.

Davidai, S., Gilovich, T. and Ross, L. 2012. "The meaning of default options for potential organ donors”, Proceedings of the National Academy of Sciences, 109 (38), 15201-15205. 
Dobbin, F. and Kalev, A. 2016. "Why Diversity Programs Fail”, Harvard Business Review, 94 (7), 52-60.

Duncan, D. and Li, D. 2016. "Liar Liar: Experimental Evidence on the Effect of Confirmation-reports on Dishonesty”.

Dunn, D., Gerlach, J. and Hyle, A. 2014. “Gender and Leadership: Reflections of Women in Higher Education Administration”, International Journal of Leadership and Change, 2 (1), 9-18.

Erkal, N., Gangadharan, L. and Nikiforakis, N. 2011. "Relative Earnings and Giving in a Real-Effort Experiment”, American Economic Review, 101 (7), 3330-3348.

Feltovich, N. and Grossman, P. J. 2012. "How does the Effect of Pre-play Suggestions Vary with Group Size? Experimental Evidence from a Threshold Public-good Game”, European Economic Review, 79, 263-280.

Fischbacher, U. 2007. "z-Tree: Zurich toolbox for ready-made economic experiments”, Experimental Economics, 10 (2), 171-178.

Flory, J., Leibbrandt, A. and List, J. 2015. “Do Competitive Workplaces Deter Female Workers? A Large-Scale Natural Field Experiment on Job Entry Decisions”, Review of Economic Studies, 82 (1), 122-155.

Gangadharan, L., Jain, T., Maitra, P. and Vecci, J. 2016. "Social Identity and Governance: The Behavioral Response to Female Leaders”, European Economic Review, 90, 302-325.

Gigerenzer, G. 2008. "Why Heuristics Work”, Perspective on Psychological Science, 3 (1), 20-29.

Gill, D. and Prowse, V. 2012. “A Structural Analysis of Disappointment Aversion in a Real Effort Competition”, American Economic Review, 102 (1), 469-503.

Gneezy, U., Niederle, M. and Rustichini, A. 2003. "Performance in Competitive Environments: Gender Differences”, Quarterly Journal of Economics, 118 (3), 1049-1074.

Gneezy, U. and Rustichini, A. 2004. "Gender and Competition at a Young Age”, American Economic Review Papers \& Proceedings, 94 (2), 377-381.

Goldin, C. and Rouse, C. 2000. "Orchestrating Impartiality: The Effect of "Blind” Auditions on Female Musicians”, American Economic Review, 90 (4), 715-741. Greiner, B. 2015. “Subject pool recruitment procedures: organizing experiments with ORSEE”, Journal of the Economic Science Association, 1 (1), 114-125. 
Houser, D., Levy, D., Padgitt, K., Peart, S. and Xiao, E. 2014. "Raising the Price of Talk: An Experimental Analysis of Transparent Leadership”, Journal of Economic Behavior and Organization, 105, 208-218.

Houser, D. and Xiao, E. 2011. “Classification of Natural Language Messages Using A Coordination Game”, Experimental Economics, 14 (1), 1-14.

Johnson, E. and Goldstein, D. 2003. “Do Defaults Save Lives?”, Science, 302 (5649), 1338-1339.

Koenig, A., Eagly, A., Mitchell, A. and Ristikari, T. 2011. “Are Leader Stereotypes Masculine? A Meta-Analysis of Three Research Paradigms”, Psychological Bulletin, 137 (4), 616-642.

Leslie, S., Cimpian, A., Meyer, M., and Freeland, E. 2015. “Expectations of brilliance underlie gender distributions across academic disciplines”, Science, 347 (6219), 262-265.

Levy, D.M., Padgitt, K., Peart, S.J., Houser, D. and Xiao, E. 2011. “Leadership, cheap talk and really cheap talk”, Journal of Economic Behavior and Organization, 77 (1), 40-52.

Li, D., Hawley, Z.B. and Schnier, K.E. 2013. "Increasing Organ Donation via Changes in the Default Choice or Allocation Rule,” Journal of Health Economics, 32(6), 1117-1129.

Madrian, B. and Shea, D. 2001. "The Power of Suggestion: Inertia In 401(k) Participation and Saving Behavior”, Quarterly Journal of Economics, 116 (4), 1149-1187.

Madsen, S. 2008. On Becoming a Woman Leader: Learning from the Experiences of University Presidents, San Francisco: Jossey-Bass.

Matsa, D. and Miller, A. 2013. “A Female Style in Corporate Leadership? Evidence from Quotas”, American Economic Journal: Applied Economics, 5 (3), 136-169.

McKenzie, C., Liersch, M. and Finkelstein, S. 2006. "Recommendations Implicit in Policy Defaults”, Psychological Science, 17 (5), 414-420.

Mulligan, C. and Rubinstein, Y. 2008. "Selection, Investment, and Women's Relative Wages Over Time”, Quarterly Journal of Economics, 123 (3), 1061-1110.

Murphy, R., Ackermann, K. and Handgraaf, M. 2011. "Measuring Social Value Orientation”, Judgment and Decision Making, 6 (8), 771-781. 
Niederle, M. and Vesterlund, L. 2007. “Do Women Shy Away From Competition? Do Men Compete Too Much?”, Quarterly Journal of Economics, 122 (3), 10671101.

Petrie, R. and Segal, C. 2015. "Gender Differences in Competitiveness: The Role of Prizes.”.

Ruble, D. N., Martin, C. L., and Berenbaum, S. A. 2006. “Gender Development”, in The Handbook of Child Psychology, Vol. 3, 6th ed., W. Damon and R. M. Lerner, eds., New York: Wiley (Chapter 14, pp. 858-932).

Smith, N.C., Goldstein, G. and Johnson, E. 2013. "Choice Without Awareness: Ethical and Policy Implications of Defaults”, Journal of Public Policy and Marketing, 32 (2), 159-172.

Thaler, R. and Benartzi, S. 2004. "Save More Tomorrow ${ }^{\mathrm{TM}}$ : Using Behavioral Economics to Increase Employee Saving”, Journal of Political Economy, 112 (1), S164-S187.

Tversky, A. and Kahneman, D. 1991. "Loss Aversion in Riskless Choice: A ReferenceDependent Model”, Quarterly Journal of Economics, 106 (4), 1039-1061.

UN Women. 2016. Annual Report 2015-2016, New York. 
Figure 1: Experiment outline

\section{Experiment I:}

Each participant works on the slider and encryption tasks.

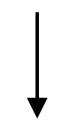

Experiment II, Stage 1:

Each participant chooses whether to compete.
Each participant chooses whether to compete conditional on rank information $\left(1^{\text {st }}, 2^{\text {nd }}, 3^{\text {rd }}\right.$, and $4^{\text {th }}$, presented in a random order).
A leader is selected according to the participants' rank and their rank-specific competition decisions.

\section{Experiment II, Stage 2:}

Participants decide how many tasks to suggest if they were to be selected as the leader.
Each participant is informed whether she/he has been selected to be the leader.
Participants decide how many additional tasks to work on.
Participants learn the selected leader's message. 
Figure 2: Competition decisions

(a) Proportion of participants who compete by treatment

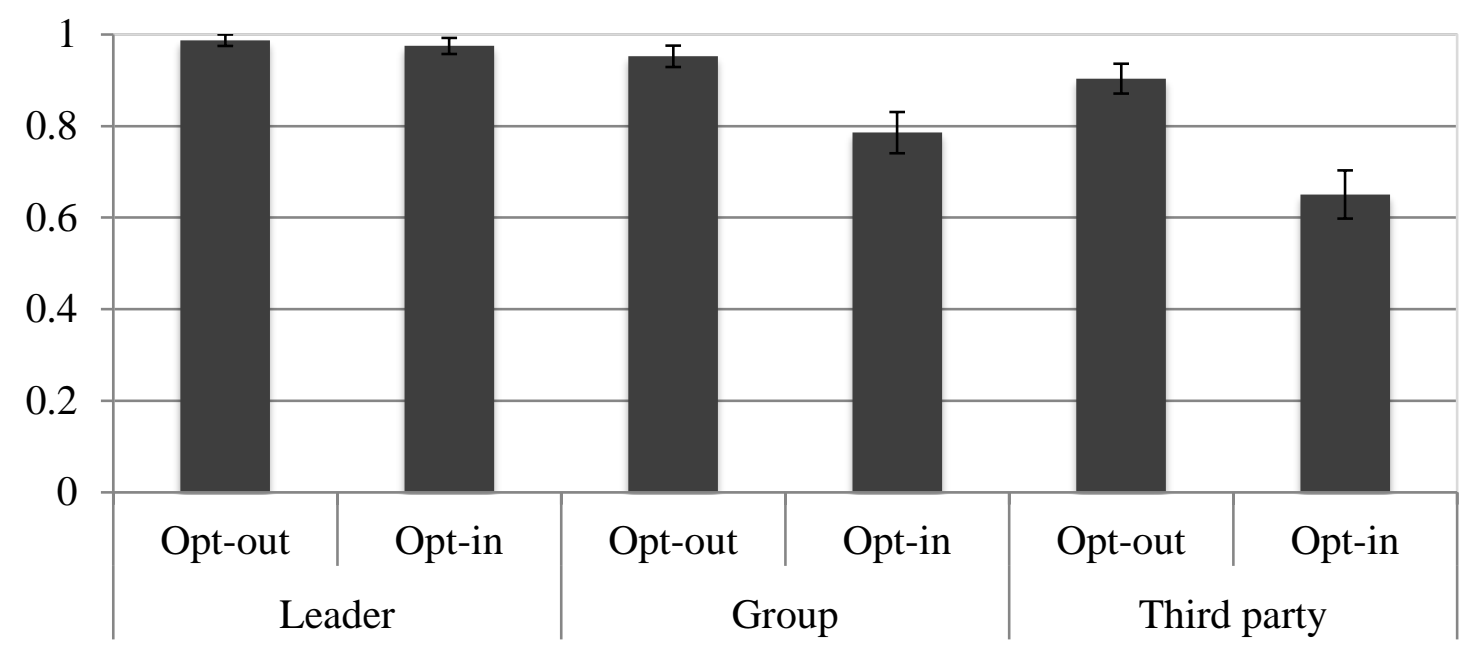

b) Proportion of participants who compete by gender and treatment

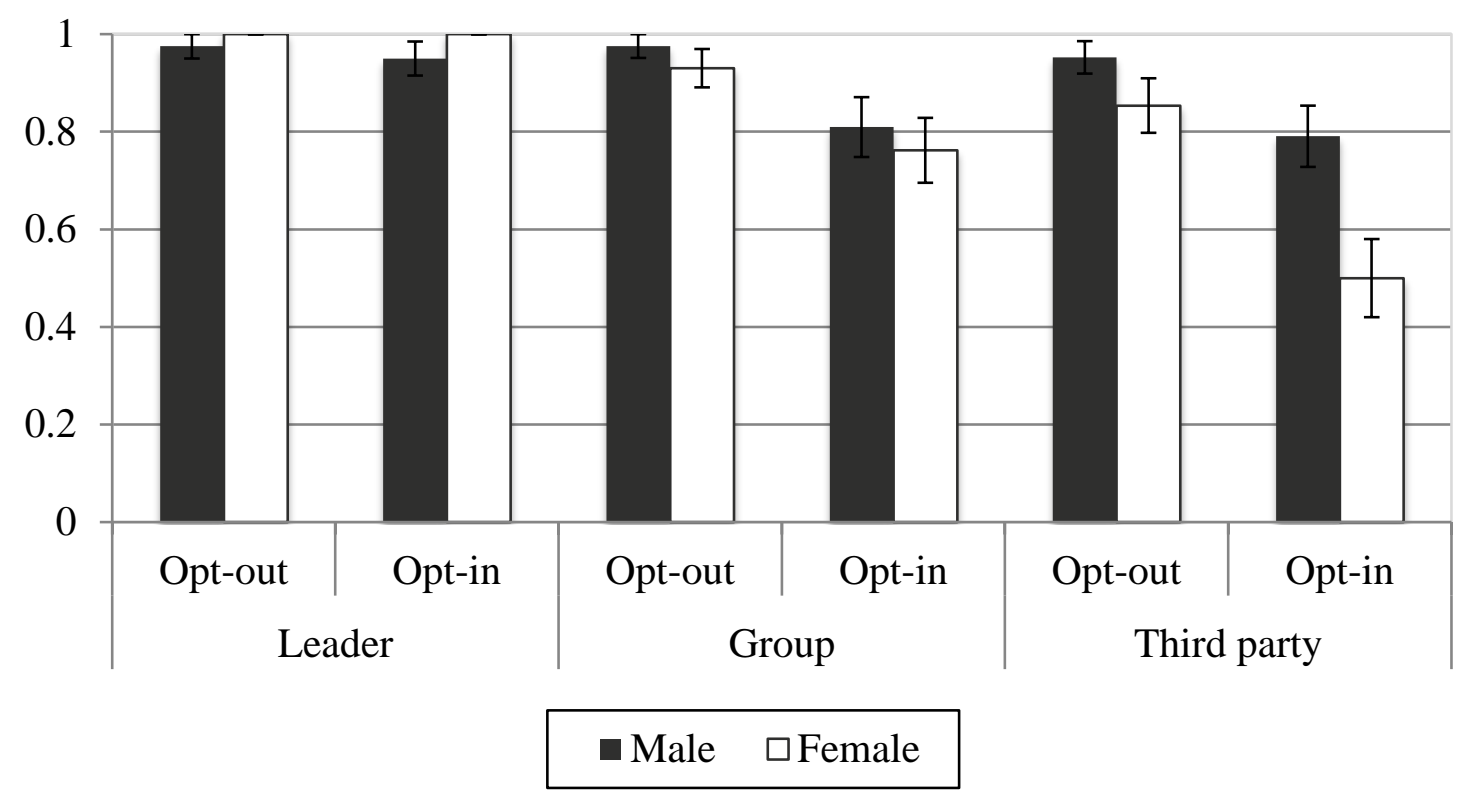


Figure 3: Proportion of subjects who compete conditional on ranking (Third-party)
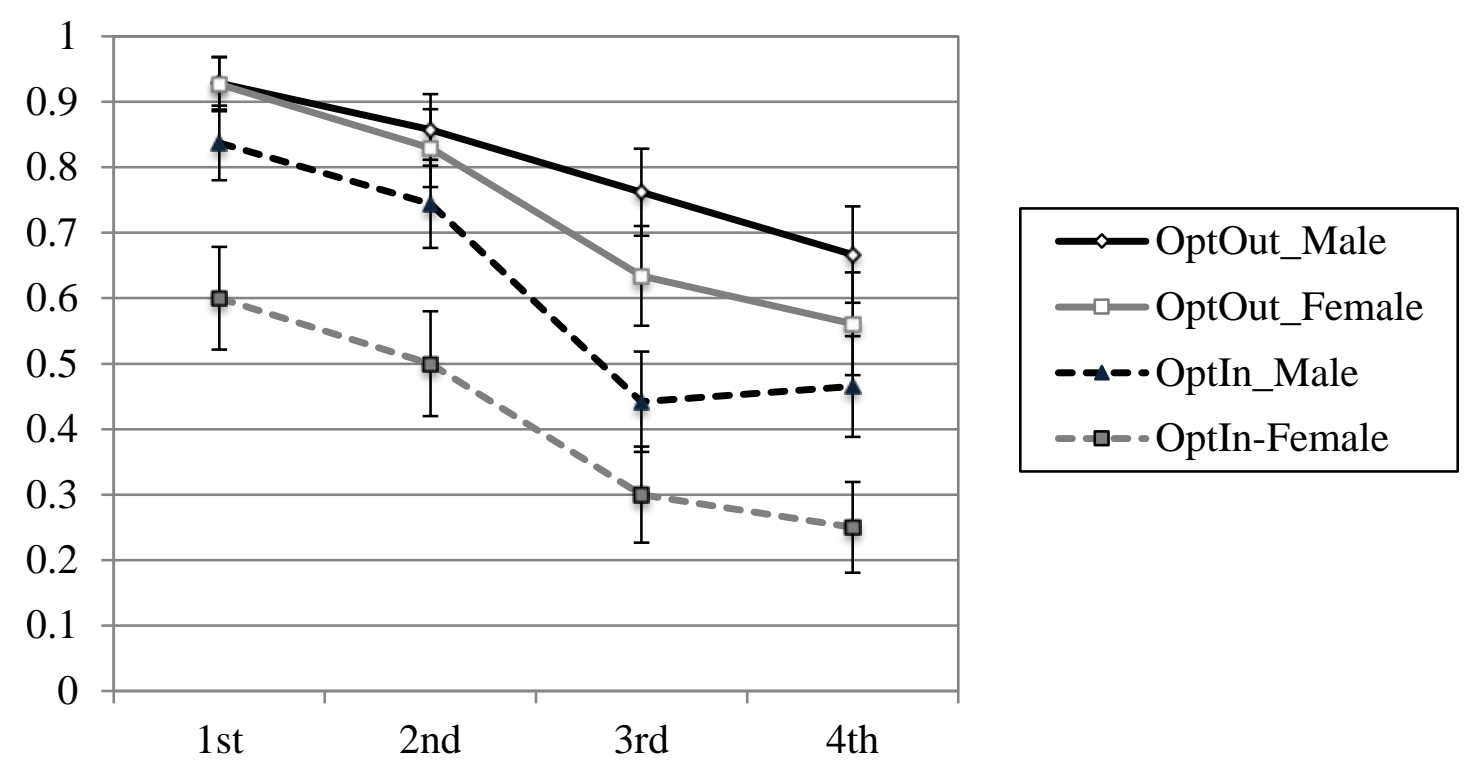

Figure 4: Choice between the two mechanisms by gender and treatment

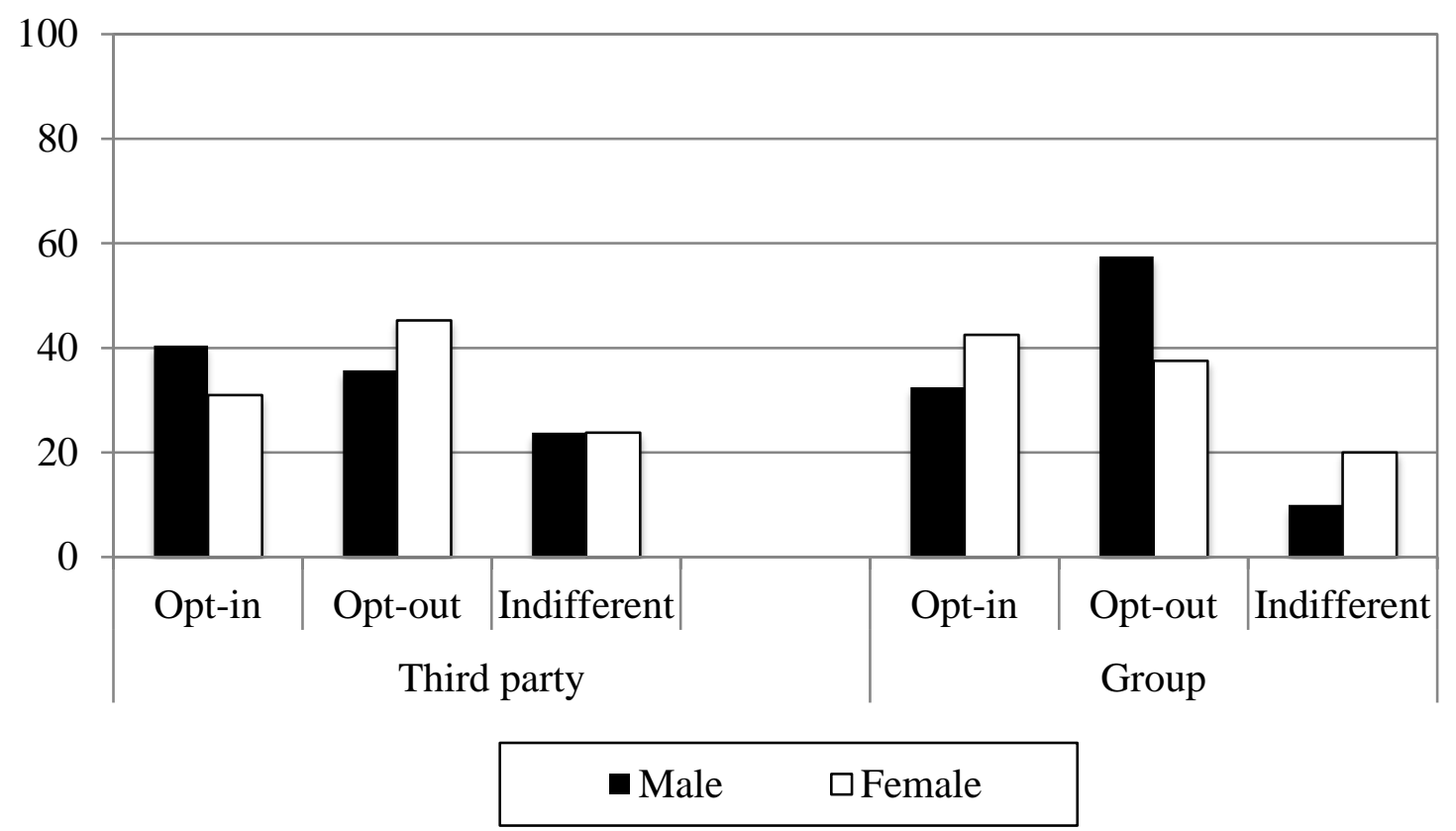


Table 1. Treatment design and number of observations (in Experiment I and Experiment II of the first study)

\begin{tabular}{|c|c|c|c|c|}
\hline \multicolumn{2}{|c|}{ Treatments } & \multicolumn{3}{|c|}{ \# of obs. } \\
\hline Leadership & Leadership & & & \\
\hline Scenario & $\begin{array}{l}\text { selection } \\
\text { mechanism }\end{array}$ & Total & Men & Women \\
\hline \multirow[t]{2}{*}{ Leader } & Opt-out & 80 & 40 & 40 \\
\hline & Opt-in & 80 & 40 & 40 \\
\hline \multirow[t]{2}{*}{ Group } & Opt-out & 84 & 41 & 43 \\
\hline & Opt-in & 84 & 42 & 42 \\
\hline \multirow[t]{2}{*}{ Third-party } & Opt-out & 84 & 42 & 42 \\
\hline & Opt-in & 84 & 43 & 41 \\
\hline
\end{tabular}


Table 2. Willingness to compete in the three leadership scenarios

Panel A: Leader scenario

\begin{tabular}{lll}
\hline \hline & Regression 1 & Regression 2 \\
\hline Opt Out & 0.025 & 0.020 \\
Female & $(0.049)$ & $(0.046)$ \\
& 0.05 & 0.056 \\
Opt Out*Female & $(0.044)$ & $(0.045)$ \\
& -0.025 & -0.030 \\
Social Value Orientation & $(0.756)$ & $(0.050)$ \\
& & -0.000 \\
Expectation of the rank & & $(0.000)$ \\
Constant & & -0.028 \\
& $0.95^{* * *}$ & $(0.024)$ \\
R-squared & $(0.044)$ & $1.009 * * *$ \\
Observations & 0.02 & $(0.023)$ \\
\hline
\end{tabular}

Notes: Numbers in the parentheses are the robust standard errors. All regressions are clustered at the session level. Significance Levels: ***: significant at the $1 \%$ level; **: significant at the $5 \%$ level: *: significant at the $10 \%$ level.

"Expectation of the rank" =1 if the participant believes his/her Experiment 1 performance is ranked in the first quartile; $=2$ if the second quartile; $=3$ if the third quartile; $=4$ if the bottom quartile. 
Panel B: Group scenario

\begin{tabular}{lll}
\hline \hline & Regression 1 & Regression 2 \\
\hline Opt Out & $0.166^{* *}$ & $0.177^{* * *}$ \\
Female & $(0.043)$ & $(0.042)$ \\
& 0.048 & -0.020 \\
Opt Out*Female & $(0.041)$ & $(0.041)$ \\
& 0.002 & -0.011 \\
Social Value Orientation & $(0.047)$ & $(0.054)$ \\
& & -0.002 \\
Expectation of the rank & & $(0.002)$ \\
Constant & & -0.075 \\
R-squared & $0.810^{* * *}$ & $(0.042)$ \\
Observations & $(0.037)$ & $0.961^{* * *}$ \\
\hline
\end{tabular}


Panel C: Third-party scenario

\begin{tabular}{lll}
\hline \hline & Regression 1 & Regression 2 \\
\hline Opt Out & $0.11^{* * *}$ & $0.154^{* * *}$ \\
Female & $(0.023)$ & $(0.035)$ \\
& $-0.290^{* * *}$ & $-0.254^{* *}$ \\
Opt Out*Female & $(0.060)$ & $(0.081)$ \\
& $0.192^{* *}$ & $0.193^{* *}$ \\
Social Value Orientation & $(0.756)$ & $(0.049)$ \\
& & -0.003 \\
Expectation of the rank & & $(0.002)$ \\
& & -0.081 \\
Constant & & $(0.049)$ \\
R-squared & $0.791^{* * *}$ & $1.007^{* * *}$ \\
Observations & $(0.009)$ & $(0.048)$ \\
\hline
\end{tabular}


Table 3. Willingness to compete conditional on rank in the Third-party scenario

Panel A

\begin{tabular}{lll}
\hline \hline & Top 2 & Bottom2 \\
\hline Opt Out & $0.102^{* *}$ & $0.261^{* * *}$ \\
Female & $(0.034)$ & $(0.054)$ \\
& $-0.241^{* * *}$ & $-0.178^{* *}$ \\
Opt Out*Female & $(0.026)$ & $(0.061)$ \\
& $0.226^{* *}$ & 0.062 \\
Constant & $(0.079)$ & $(0.068)$ \\
& $0.791^{* * *}$ & $0.453^{* * *}$ \\
R-squared & $(0.028)$ & $(0.022)$ \\
Observations & 0.126 & 0.118 \\
\hline
\end{tabular}

Notes: Numbers in the parentheses are the robust standard errors. All regressions are clustered at the session level. Significance Levels: ***: significant at the $1 \%$ level; **: significant at the $5 \%$ level: *: significant at the $10 \%$ level. 
Panel B

\begin{tabular}{lll}
\hline \hline & Coefficient & Robust s.e. \\
\hline$\beta_{1}:$ Top2*Female*Opt Out & $0.321^{* * *}$ & 0.073 \\
$\beta_{2}:$ Top2*Male*Opt Out & $0.275^{* * *}$ & 0.036 \\
$\beta_{3}:$ Top2*Female*Opt In & $0.162^{* * *}$ & 0.046 \\
$\beta_{4}:$ Top2*Male*Opt In & $0.309^{* * *}$ & 0.055 \\
Constant & & \\
Wald chi2(4) & $0.512^{* * *}$ & 0.069 \\
Observations & 286.85 & \\
\end{tabular}

$\begin{array}{lll}\beta_{1} \text { vs. } \beta_{2} & \operatorname{chi} 2(1)=0.47 & \mathrm{p}=0.494 \\ \beta_{3} \text { vs. } \beta_{4} & \operatorname{chi} 2(1)=85.86 & \mathrm{p}=0.000 \\ \beta_{1}-\beta_{2} \text { vs. } \beta_{3}-\beta_{4} & \operatorname{chi} 2(1)=7.71 & \mathrm{p}=0.006\end{array}$

Notes: All regressions are clustered at the session level. The regressions allow for a random effects error structure. Significance Levels: ***: significant at the $1 \%$ level; **: significant at the $5 \%$ level: *: significant at the $10 \%$ level. 
Table 4. Number of additional tasks suggested in the Third-party scenario

a) Opt-out vs. Opt-in

\begin{tabular}{|c|c|c|}
\hline & & $\begin{array}{l}\text { Mean } \\
\text { (s.e.) }\end{array}$ \\
\hline \multirow{5}{*}{ Competitors $^{2}$} & Opt-out & 19.31 \\
\hline & $((\#$ of obs.: 75$)$ & (1.49) \\
\hline & Opt-in & 18.81 \\
\hline & (\# of obs.: 54 ) & $(1.80)$ \\
\hline & p-value $^{1}$ & 0.788 \\
\hline \multirow{5}{*}{ Elected Leader ${ }^{3}$} & Opt-out & 16.76 \\
\hline & (\# of obs.: 21) & $(2.43)$ \\
\hline & Opt-in & 21.48 \\
\hline & (\# of obs.: 21) & (3.15) \\
\hline & p-value & 0.326 \\
\hline \multicolumn{3}{|c|}{${ }^{1} \mathrm{p}$-value is for the Mann-Whitney test of the difference between Opt-out and Opt-in } \\
\hline \multicolumn{3}{|c|}{$\begin{array}{l}{ }^{2} \text { Competitors are the participants who chose to compete for the leadership position } \\
\text { without knowing their performance rank. }\end{array}$} \\
\hline \multicolumn{3}{|c|}{${ }^{3}$ Standard errors are calculated using each group as an independent observation and are } \\
\hline
\end{tabular}


Table 5. Number of additional tasks completed by participants in the Third-party scenario

\begin{tabular}{|c|c|c|}
\hline & & $\begin{array}{l}\text { Mean } \\
\text { (s.e.) }\end{array}$ \\
\hline \multirow{5}{*}{ Non-leaders } & Opt-out & 24.23 \\
\hline & (\# of obs.: 62) & (1.73) \\
\hline & Opt-in & 24.90 \\
\hline & (\# of obs.: 62) & (1.78) \\
\hline & p-value ${ }^{1}$ & 0.711 \\
\hline \multirow{5}{*}{ Elected leaders } & Opt-out & 27.81 \\
\hline & (\# of obs.: 21) & (3.13) \\
\hline & Opt-in & 25.05 \\
\hline & (\# of obs.: 21) & (3.21) \\
\hline & p-value & 0.542 \\
\hline
\end{tabular}

$\overline{1}$ p-value is for the Mann-Whitney test of the difference between the Opt-out and Optin mechanisms. 


\section{Appendix A.}

The following are the instructions for the Third-party scenario. We mark the parts where the instructions differ between the Opt-in and Opt-out treatments.

[Opt-in and Opt-out]

\section{INSTRUCTIONS}

Thank you for coming! You've earned \$10 for showing up on time, and the instructions explain how you can make decisions and earn more money. So please read these instructions carefully. There should be no talking at any time during this experiment. If you have any questions, please raise your hand and an experimenter will assist you.

All the decisions will be made anonymously. You will never be informed of the identity of any other participants, either during or after the experiment. Similarly, other participants will never be informed of your identity.

You are going to participate in two experiments today: Experiment I and Experiment II. Your earnings in Experiment I will not be affected by your decisions in Experiment II. That is, nothing you do in Experiment II can change your earnings in Experiment I.

At the end of Experiment II, you will be asked to fill out a brief questionnaire asking you some general questions. At the end of today's session, either Experiment I or Experiment II, but not both, will be randomly selected for payment. Your earnings from this randomly selected experiment will be paid to you privately in cash at the end of the session.

You will now receive the instructions for Experiment I. You will receive the instructions for Experiment II after Experiment I ends. 


\section{Experiment I}

Experiment I consists of two activities: Activity 1 and Activity 2. The activities will appear in an alternating fashion on your screen. All participants will be given the two activities in the same order. You will have 10 minutes to work on the two activities.

Activity 1: In this activity, you will be presented with a series of words. You will be asked to encode these words by substituting the letters of the alphabet with numbers using an encoding table which will be provided on their screens. Every time a word is encoded correctly, the encoding table will change.

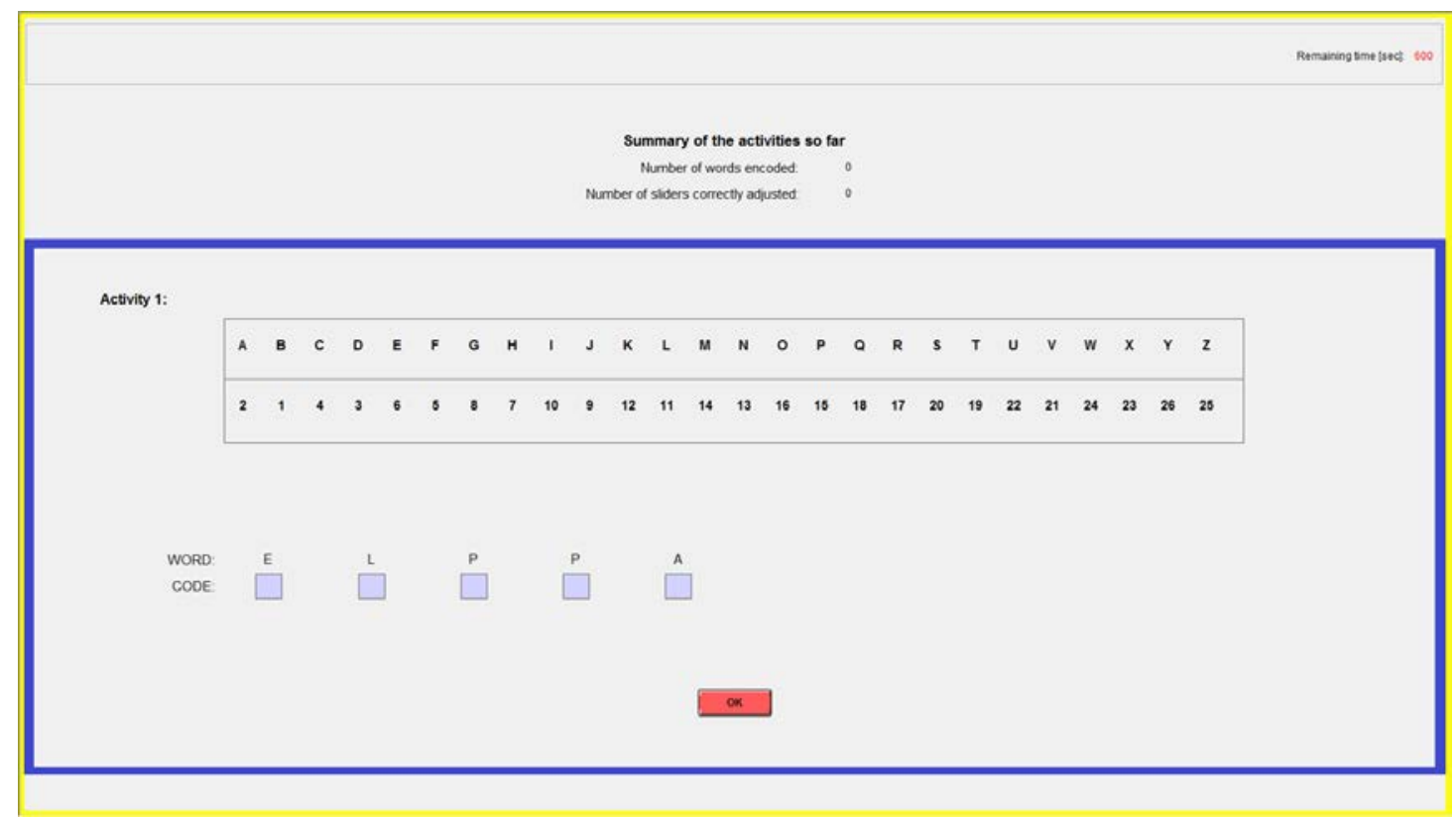

Figure 1

Figure 1 shows an example of a word (ELPPA) to be encoded. The table given on the screen shows that $E=6, L=11, P=15, P=15$, and $A=2$.

Activity 2: You will be presented with a series of sliders. Each slider is initially positioned at 0 and can be moved as far as 100. Each slider has a number to its left showing its target position, and a number to its right showing its current position. You are asked to adjust each slider to its target position.

Each screen consists of 3 sliders. You can use the mouse to move each slider, and you can adjust the position of each slider as many times as you wish. All subjects will be given the same set of sliders in the same sequence. However, you can adjust the sliders in whichever order you prefer.

Figure 2 shows an example of a set of 3 sliders to be adjusted. In this example, you will need to adjust the first slider to a position of 23, the second slider to a position of 53, and the third slider to a position of 80 . 


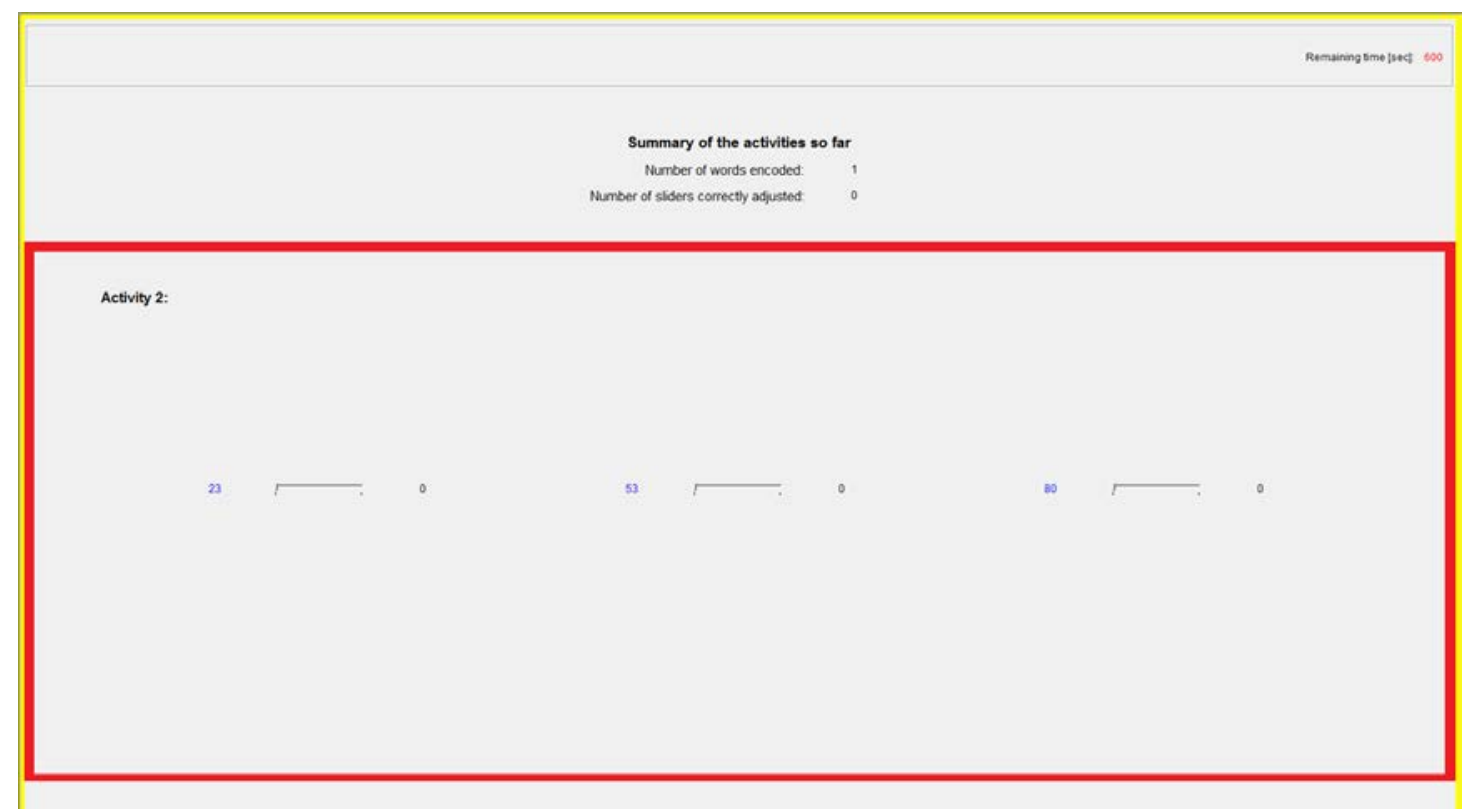

Figure 2

Your payment in Experiment I will be determined by the number of words you encode correctly and the number of sliders you position correctly. For each word you encode correctly, you will earn \$0.50 (50 cents). For each slider you position correctly, you will earn $\$ 0.25$ (25 cents). Thus, your earnings in Experiment I will be equal to:

(\$0.50 x number of words you encoded correctly)

$+(\$ 0.25 \mathrm{x}$ number of sliders you positioned correctly)

\section{Summary:}

- In Experiment I, you will participate in two activities for 10 minutes.

- Your earnings will depend on your performance in these two activities. You will receive $\$ 0.50$ for each word you encode correctly and $\$ 0.25$ for each slider you position correctly.

\section{End of Instructions for Experiment I}

If you have any questions, please raise your hand. Otherwise, please wait for the experimenter to launch the practice questions on the computer screen after everyone finishes reading the instructions. The purpose of these questions is to make sure that you understand the experiment. 


\section{Experiment II}

This is the final experiment of today's session. At the end of today's session, either Experiment I or Experiment II, but not both, will be randomly selected for payment. Any money that you earn in this randomly selected experiment will be added to your \$10 show-up payment and paid to you in cash at the end of the session.

You will form a group with three other participants randomly selected by the computer. You will never be informed of the identity of any of your group members, either during or after the experiment. Similarly, your group members will never be informed of your identity. This experiment consists of two stages.

Stage 1: Leadership selection

In this stage, a leader will be selected for each group. The role of the leader is explained below in the explanation of Stage 2.

\section{[Opt-in]}

The computer will randomly select one participant to be the leader. However, you can indicate it if you have a desire to compete for the leader position. The computer's random assignment will be implemented unless at least one participant in your group indicates a desire to compete, in which case the leader will be selected as follows:

- If only one participant indicates such a desire, this participant will be the leader.

- If more than one participant indicates such a desire, these participants will compete for the leader position based on their performance in Experiment I. Specifically, among the competitors, the computer will select the participant who has the highest performance in Experiment I as the leader. (Ties will be broken randomly.)

Figure 3 shows the screen where you can indicate your desire to compete for the leader position. You will see the statement "I do NOT want to compete for the leader position" checked on your screen. To indicate your desire to compete for the leader position, you need to uncheck this and, instead, check the statement "I want to compete for the leader position".

\section{[Opt-out]}

Every participant will compete for the leader position based on his/her performance in Experiment I. Specifically, the computer will select the participant who has the highest performance in Experiment I as the leader. (Ties will be broken randomly.) However, you can indicate it if you have a desire NOT to compete for the leader position. Everyone will compete for the leader position and the computer will select the participant with the highest performance in Experiment I to be the leader unless at least one participant in your group indicates a desire NOT to compete, in which case the leader will be selected as follows:

- If some but not all participants indicate a desire NOT to compete for the leader position, the computer will select, among the remaining competitors, the participant who has the highest performance in Experiment I as the leader.

- If all participants indicate a desire NOT to compete for the leader position, the computer will randomly select one participant to be the leader. 
Figure 3 shows the screen where you can indicate your desire NOT to compete for the leader position. You will see the statement "I want to compete for the leader position" checked on your screen. To indicate your desire NOT to compete for the leader position, you need to uncheck this and, instead, check the statement "I do NOT want to compete for the leader position".

[Opt-in and Opt-out]

You choice on this screen is your private information and will never be revealed to any other participant.

After every one has completed the screen, a leader will be selected according to the rules described above.

[Opt-in]

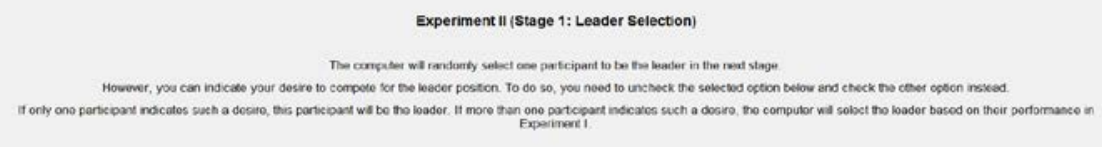

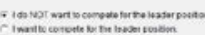

\section{Figure 3}

[Opt-out]

Experiment III Istage 1: Leader Selection

Eron

The

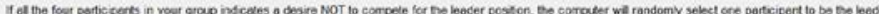

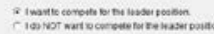

Figure 3 


\section{[Opt-in and Opt-out]}

Stage 2: Working on tasks

Each participant in your group (both the leader and the others) will have an opportunity to work on a counting activity. You will be given a table filled with numbers and your task is to count the number of " 0 " in the table. Figure 4 shows the screen for the counting table.

Each participant will earn $\$ 20$ as long as s/he completes 20 counting tables correctly, and zero otherwise. The computer will show whether you have correctly completed a table or not after each table. Thus, each participant will be notified once s/he has finished 20 tables correctly and has earned the \$20.

After this, each participant can continue to work on additional tables up to 40 tables if s/he wants. Any additional table a participant completes correctly will help a charity, but not anyone in the group. Specifically, each correctly completed table will raise $\$ 0.25$ (25 cents) for one of the five charities listed below. At the end of the session, the computer will randomly determine which charity will receive the donations from each group. The earnings from the total number of additional tables completed by the group members will then be donated to this charity. Once this donation is completed, you will receive a copy of the receipt as confirmation of your group's donation.

The computer will pick one of the following five charities in a random fashion:

- Australian Cancer Research Foundation: A cancer charity foundation dedicated to finding the cures for cancer by funding world-class cancer research in Australia.

- Earthwatch Institute: An international charity that promotes the understanding and action necessary for a sustainable environment through education and scientific research.

- Habitat for Humanity Australia: An organization that provides appropriate housing solutions in sustainable communities.

- Headspace: An organization that provides early interventional mental health services to youth between 12 and 25 years old.

- Starlight Children's Foundation: An organization whose mission is to brighten the lives of seriously ill children and their families.

You will be asked to state how many additional tables you would like to work on. If you choose not to work on additional tables, you may browse the Internet while you are waiting for the other participants to finish their activities. 


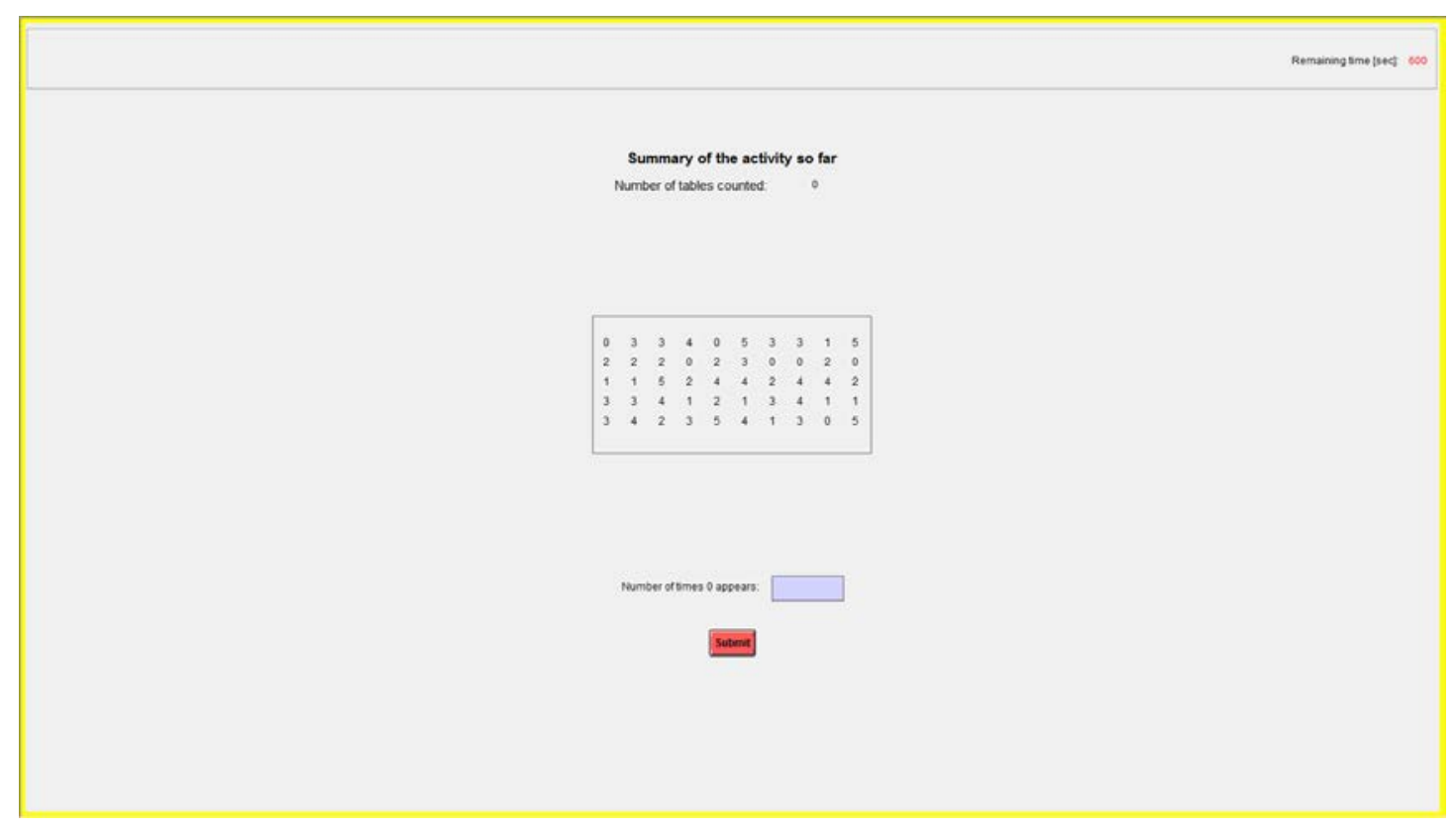

Figure 4

Example: Consider a group where, after each group member (including the leader) has completed 20 tables and earned \$20, one group member completes 5 additional tables, another one completes 10 additional tables, a third one completes zero additional tables. The leader completes 9 additional tables. In this case, the charity receives $\$ 0.25 \times$ ( $5+$ $10+9)=\$ 6$. Each group member’s final earnings are $\$ 20$.

Role of the leader: At the beginning of this stage, the leader of each group can send the following message to the group members:

"Please complete at least more tables after you finished your own 20 tables.”

The leader can choose any number between 0 and 40 since the group members are allowed to work on 40 additional tables at the most. Each group member will see the leader's message before starting to work on additional tables. The leader's message is only suggestive and each group member can decide on his/her own whether to work on additional tables after finishing the first 20 tables.

The total number of tables completed by each participant is private information and will never be revealed to any other participant. At the end of today's session, the group members will see the total number of additional tables completed by the group when they learn how much the charity will receive. However, they will never be informed about the number of additional tables completed by any individual participant in the group.

\section{Summary:}

- Experiment II consists of two stages. You will participate in Experiment II in groups of four. You will never be informed of the identity of your group members. [Opt-in]

- Stage 1 is the leadership selection stage. The computer will randomly select one participant to be the leader. However, you can indicate it if you have a desire to compete for the leader position. Then, the computer will select a leader amongst 
those participants who express a desire to compete for the leader position based on their performance in Experiment I.

[Opt-out]

- Stage 1 is the leadership selection stage. Everyone will compete for the leader position and the computer will select the person with the highest performance in Experiment I to be the leader unless at least one participant in your group indicates a desire NOT to compete. Then, the computer will select a leader amongst those participants who do NOT express a desire NOT to compete for the leader position based on their performance in Experiment I.

[Opt-in and Opt-out]

- In Stage 2, the group members will work on a counting tables task. Each group member will earn a fixed amount of $\$ 20$ as long as s/he finishes the 20 tables correctly, and zero otherwise.

- The leader can send a message to the group asking each member to work on additional counting tables after the first 20 tables.

- Working on additional tables is optional. Each group member can work on up to 40 additional tables if s/he wants. If you choose not to work on additional tables, you may browse the Internet while you wait for the others.

- Any earnings from the additional tables completed by the group will be donated to a charity randomly determined by the computer. The additional tables will not affect the payments received by the group members.

\section{End of Instructions for Experiment II}

If you have any questions, please raise your hand. Otherwise, please wait for the experimenter to launch the practice questions on the computer screen after everyone finishes reading the instructions. Again, the purpose of these questions is to make sure that you understand the experiment. 


\section{Appendix B.}

These are the instructions used in Part 1 of the second study for the Third-party scenario.

\section{INSTRUCTIONS}

Thank you for coming! You've earned \$10 for showing up on time, and the instructions explain how you can make decisions and earn more money. So please read these instructions carefully. There should be no talking at any time during this experiment. If you have any questions, please raise your hand and an experimenter will assist you.

All the decisions will be made anonymously. You will never be informed of the identity of any other participants, either during or after the experiment. Similarly, other participants will never be informed of your identity.

You are going to participate in two experiments today: Experiment I and Experiment II. Your earnings in Experiment I will not be affected by your decisions in Experiment II. That is, nothing you do in Experiment II can change your earnings in Experiment I.

At the end of Experiment II, you will be asked to fill out a brief questionnaire asking you some general questions. At the end of today's session, either Experiment I or Experiment II, but not both, will be randomly selected for payment. Your earnings from this randomly selected experiment will be paid to you privately in cash at the end of the session.

You will now receive the instructions for Experiment I. You will receive the instructions for Experiment II after Experiment I ends. 


\section{Experiment I}

(The instructions for Experiment I are the same as the instructions for Experiment I in the first study and can be found in Appendix A.)

\section{Experiment II}

This is the final experiment of today's session. At the end of today's session, either Experiment I or Experiment II, but not both, will be randomly selected for payment. Any money that you earn in this randomly selected experiment will be added to your $\$ 10$ show-up payment and paid to you in cash at the end of the session.

You will form a group with three other participants randomly selected by the computer. You will never be informed of the identity of any of your group members, either during or after the experiment. Similarly, your group members will never be informed of your identity. This experiment consists of three stages.

STAGE 1: Choosing the leadership selection method

There will be a leader selected for each group. The role of the leader is explained below in the explanation of Stage 3. The leader can be selected using one of two methods. The goal of this stage is to determine how the leader will be selected in your group. Below, we explain the two methods in which the leader can be selected. Each participant of the group is asked to choose the method that he/she prefers. The computer will randomly pick one participant in the group and the leader will be selected according to the method chosen by that participant.

Method Y: Under Method Y, each participant will compete for the leader position based on his/her performance in Experiment I. The computer will select the participant who has the highest performance in Experiment I as the leader. (Ties will be broken randomly.) However, each participant can indicate it if he/she has a desire NOT to compete for the leader position. Everyone will compete for the leader position and the computer will select the participant with the highest performance in Experiment I to be the leader unless at least one participant in your group indicates a desire NOT to compete, in which case the leader will be selected as follows:

- If some but not all participants indicate a desire NOT to compete for the leader position, the computer will select, among the remaining competitors, the participant who has the highest performance in Experiment I as the leader.

- If all participants indicate a desire NOT to compete for the leader position, the computer will randomly select one participant to be the leader.

Figure 3 shows the screen where each participant can indicate his/her desire NOT to compete for the leader position under Method Y. You will see the statement "I want to compete for the leader position" checked on your screen. To indicate your desire NOT to compete for the leader position, you need to uncheck this and, instead, check the statement "I do NOT want to compete for the leader position".

You choice on this screen is your private information and will never be revealed to any other participant.

After every one has completed the screen, a leader will be selected according to the rules described above. 


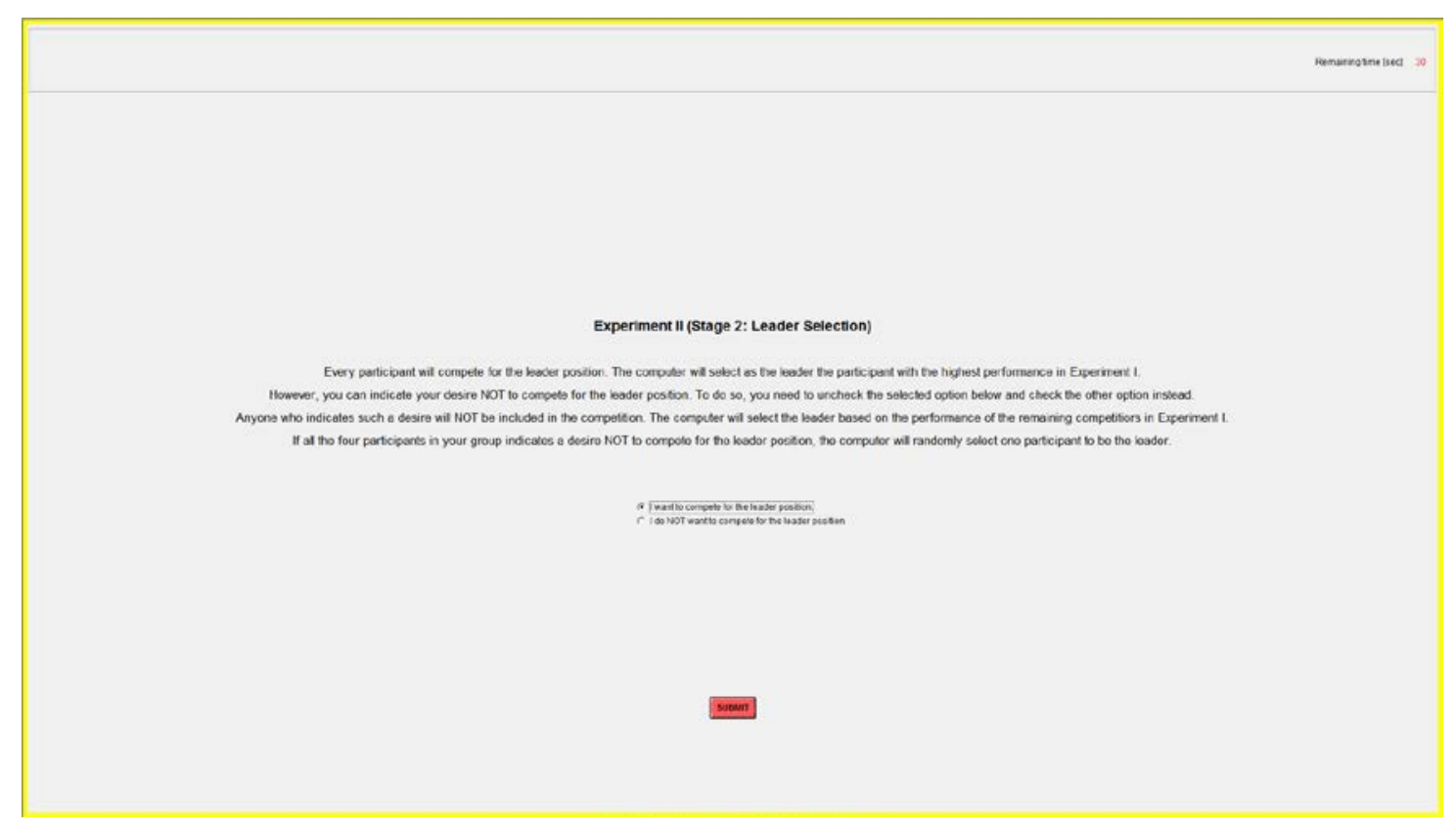

Figure 3

Method X: Under Method X, the computer will randomly select one participant to be the leader. However, each participant can indicate it if he/she has a desire to compete for the leader position. The computer's random assignment will be implemented unless at least one participant in your group indicates a desire to compete, in which case the leader will be selected as follows:

- If only one participant indicates such a desire, this participant will be the leader.

- If more than one participant indicates such a desire, these participants will compete for the leader position based on their performance in Experiment I. Specifically, among the competitors, the computer will select the participant who has the highest performance in Experiment I as the leader. (Ties will be broken randomly.)

Figure 4 shows the screen where each participant can indicate his/her desire to compete for the leader position under Method X. You will see the statement "I do NOT want to compete for the leader position" checked on your screen. To indicate your desire to compete for the leader position, you need to uncheck this and, instead, check the statement "I want to compete for the leader position".

You choice on this screen is your private information and will never be revealed to any other participant.

After every one has completed the screen, a leader will be selected according to the rules described above.

After each participant has made the decision which method he/she would choose, the computer will randomly implement the choice of one participant of the group. As a result, you will be notified whether, for your group, Method X or Method Y will be used in leadership selection. 


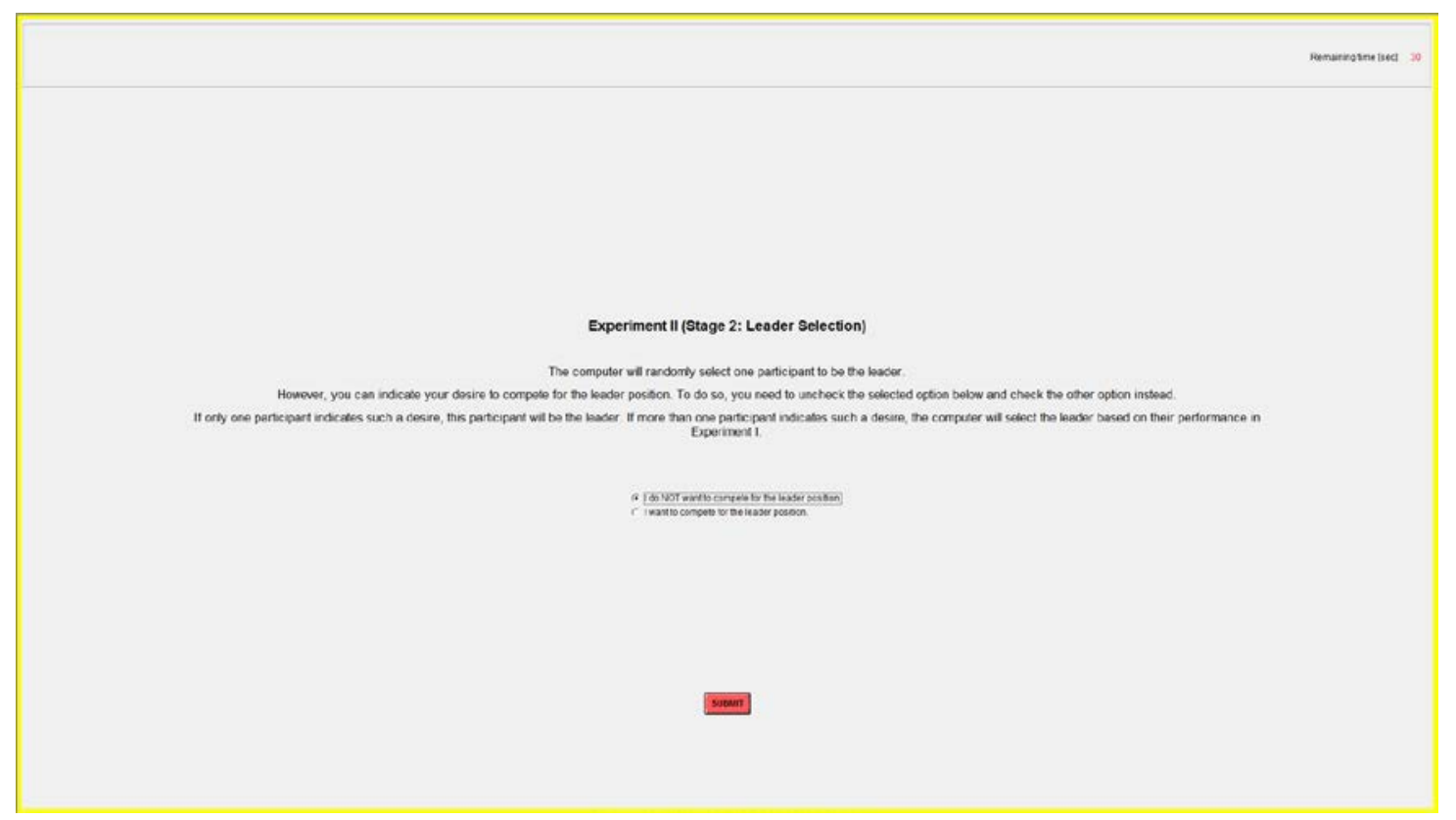

Figure 4

STAGE 2: Leadership selection

In this stage, a leader will be selected for each group according to the outcome of Stage 1. You will indicate your decision on the screen as shown in either Figure 3 or Figure 4 depending on which selection method is implemented.

STAGE 3: Working on tasks

Once the leader is determined, each participant in your group (both the leader and the others) will have an opportunity to work on a counting activity. You will be given a table filled with numbers and your task is to count the number of " 0 " in the table. Figure 5 shows the screen for the counting table.

Each participant will earn $\$ 20$ as long as s/he completes 20 counting tables correctly, and zero otherwise. The computer will show whether you have correctly completed a table or not after each table. Thus, each participant will be notified once s/he has finished 20 tables correctly and has earned the \$20.

After this, each participant can continue to work on additional tables up to 40 tables if s/he wants. Any additional table a participant completes correctly will help a charity, but not anyone in the group. Specifically, each correctly completed table will raise \$0.25 (25 cents) for one of the five charities listed below. At the end of the session, the computer will randomly determine which charity will receive the donations from each group. The earnings from the total number of additional tables completed by the group members will then be donated to this charity. Once this donation is completed, you will receive a copy of the receipt as confirmation of your group's donation.

The computer will pick one of the following five charities in a random fashion:

- Australian Cancer Research Foundation: A cancer charity foundation dedicated to finding the cures for cancer by funding world-class cancer research in Australia. 
- Earthwatch Institute: An international charity that promotes the understanding and action necessary for a sustainable environment through education and scientific research.

- Habitat for Humanity Australia: An organization that provides appropriate housing solutions in sustainable communities.

- Headspace: An organization that provides early interventional mental health services to youth between 12 and 25 years old.

- Starlight Children's Foundation: An organization whose mission is to brighten the lives of seriously ill children and their families.

You will be asked to state how many additional tables you would like to work on. If you choose not to work on additional tables, you may browse the Internet while you are waiting for the other participants to finish their activities.

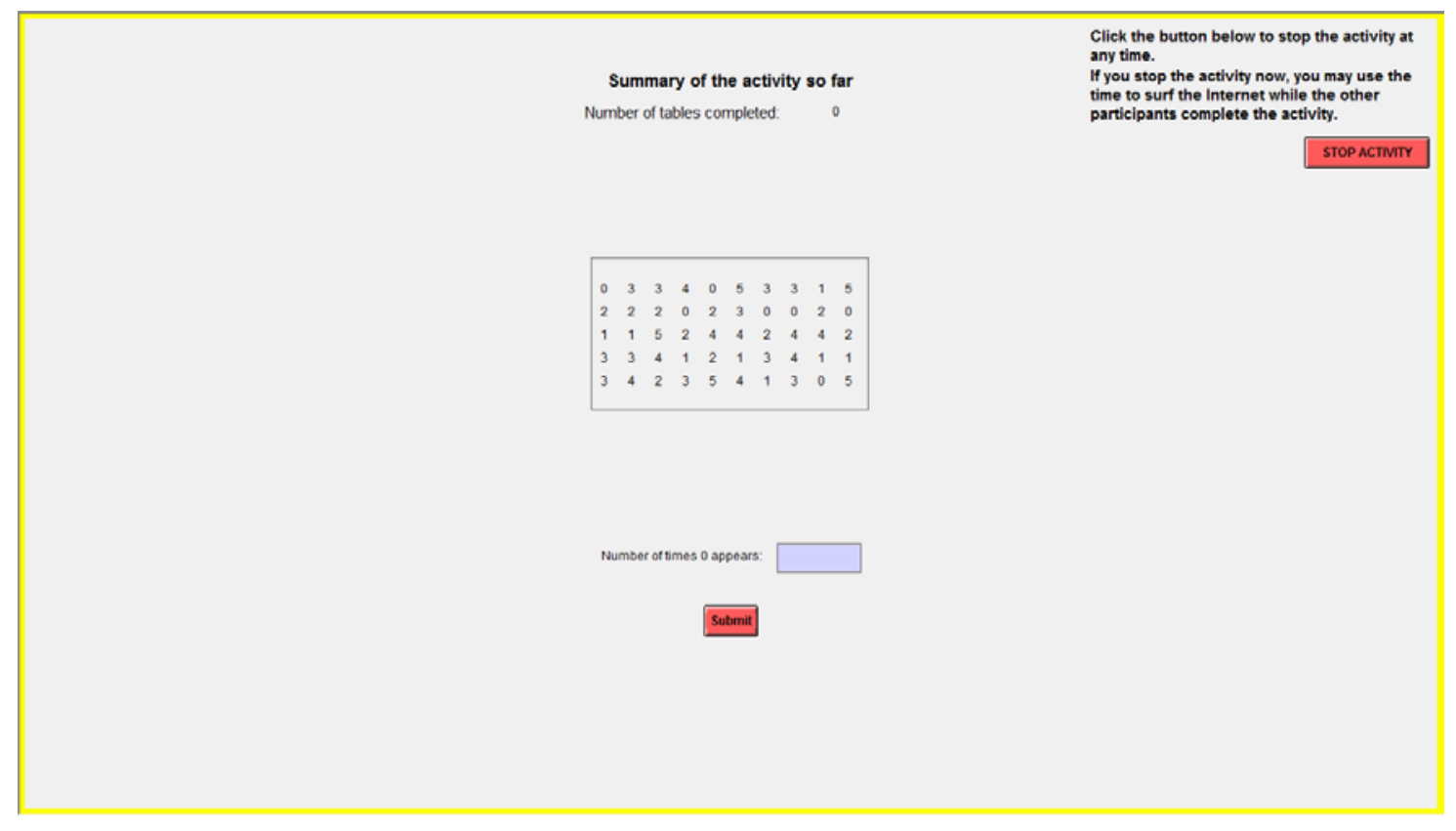

Figure 5

Example: Consider a group where, after each group member (including the leader) has completed 20 tables and earned \$20, one group member completes 5 additional tables, another one completes 10 additional tables, a third one completes zero additional tables. The leader completes 9 additional tables. In this case, the charity receives $\$ 0.25 \times$ ( $5+$ $10+9)=\$ 6$. Each group member’s final earnings are \$20.

Role of the leader: At the beginning of this stage, the leader of each group can send the following message to the group members:

"Please complete at least more tables after you finished your own 20 tables.”

The leader can choose any number between 0 and 40 since the group members are allowed to work on 40 additional tables at the most. Each group member will see the leader's message before starting to work on additional tables. The leader's message is 
only suggestive and each group member can decide on his/her own whether to work on additional tables after finishing the first 20 tables.

The total number of tables completed by each participant is private information and will never be revealed to any other participant. At the end of today's session, the group members will see the total number of additional tables completed by the group when they learn how much the charity will receive. However, they will never be informed about the number of additional tables completed by any individual participant in the group.

\section{Summary:}

- Experiment II consists of three stages. You will participate in Experiment II in groups of four. You will never be informed of the identity of your group members.

- In Stage 1, two leader selection methods are given. Each participant states whether he/she would like the leader to be selected according to Method X or Method Y. The computer then randomly picks one participant in the group and implements the choice of this participant.

- Stage 2 is the leadership selection stage. According to the outcome of Stage 1, either Method X or Method Y will be used to select the leader in Stage 2.

$\mathrm{o}$ If Method $\mathrm{X}$ is implemented, the computer will randomly select one participant to be the leader. However, each participant can indicate it if he/she has a desire to compete for the leader position. Then, the computer will select a leader amongst those participants who express a desire to compete for the leader position based on their performance in Experiment I.

o If Method Y is implemented, everyone will compete for the leader position and the computer will select the person with the highest performance in Experiment I to be the leader unless at least one participant in your group indicates a desire NOT to compete. Then, the computer will select a leader amongst those participants who do NOT express a desire NOT to compete for the leader position based on their performance in Experiment I.

- In Stage 3, the group members will work on a counting tables task. Each group member will earn a fixed amount of $\$ 20$ as long as s/he finishes the 20 tables correctly, and zero otherwise.

- The leader can send a message to the group asking each member to work on additional counting tables after the first 20 tables.

- Working on additional tables is optional. Each group member can work on up to 40 additional tables if s/he wants. If you choose not to work on additional tables, you may browse the Internet while you wait for the others.

- Any earnings from the additional tables completed by the group will be donated to a charity randomly determined by the computer. The additional tables will not affect the payments received by the group members.

\section{End of Instructions for Experiment II}

If you have any questions, please raise your hand. Otherwise, please wait for the experimenter to launch the practice questions on the computer screen after everyone finishes reading the instructions. Again, the purpose of these questions is to make sure that you understand the experiment. 


\section{Appendix C.}

These are the instructions used in Part 2 of the second study.

\section{INSTRUCTIONS}

Thank you for coming! You've earned \$10 for showing up on time, and the following instructions will explain your task in this session.

\section{$\underline{\text { Your task: }}$}

You will be given a list of messages. Your task is to classify the messages according to the categories given to you. You may pick multiple categories for the same message.

The messages were written by participants in another experiment. The experiment consisted of two parts: Experiment I and Experiment II. Participants received the instructions for Experiment II only after they all finished Experiment I. At the end of the session, one of the two experiments was randomly selected and each participant received the earnings from this randomly selected experiment.

The following is a summary of the experiment:

- Experiment I: Each participant worked on two tasks individually. Their earnings in Experiment I depended on the number of tasks they completed in 10 minutes.

- Experiment II: Four participants formed a group. There were three stages. In Stage 1, two leader selection methods were given. Each participant stated whether he/she would like the leader to be selected according to Method X or Method Y. The computer then randomly picked one participant in the group and implemented the choice of this participant.

Stage 2 was the leadership selection stage. According to the outcome of Stage 1, either Method X or Method Y was used to select the leader in Stage 2.

$\mathrm{O}$ If Method $\mathrm{X}$ was implemented, the computer randomly selected one participant to be the leader. However, each participant could indicate it if he/she had a desire to compete for the leader position. Then, the computer selected a leader amongst those participants who expressed a desire to compete for the leader position based on their performance in Experiment I.

o If Method Y was implemented, everyone competed for the leader position and the computer selected the person with the highest performance in Experiment I to be the leader unless at least one participant in the group indicated a desire NOT to compete. Then, the computer selected a leader amongst those participants who did NOT express a desire NOT to compete for the leader position based on their performance in Experiment I.

In Stage 3, the group members worked on a counting tables task. Each group member (including the leader) earned a fixed amount of $\$ 20$ as long as s/he finished the 20 tables correctly, and zero otherwise. The leader could send a message to the group asking each member to work on additional counting tables after the first 20 tables. The leader's message was only suggestive and each group member could 
decide on his/her own whether to work on additional tables after finishing the first 20 tables. Each additional table completed contributed \$0.25 (25 cents) for one of the five charities listed in the instructions. At the end of the session, the computer randomly determined which charity would receive the donations from each group. The earnings from the total number of additional tables completed by the group members were then donated to this charity.

At the end of the experiment, each participant is asked to fill out a survey. The messages you will be asked to evaluate are the participants' explanations for their decisions in Stage 1 of Experiment II. Specifically, the question is:

In Stage 1 of Experiment II, you chose the following method: (Method X / Method Y / Indifferent). Please explain your decision.

While for coding the messages, please use the following reasons:

\section{Reasons related to fairness.}

You should assign a message to this category, if you think the message writer suggested in the message that he/she was considering which mechanism was more fair.

2. Reasons related to giving people the freedom to choose.

You should assign a message to this category, if you think the message writer suggested in the message that he/she was considering whether one mechanism was more/less coercive or provided less/more freedom to people in making their own decision about leadership.

3. Reasons related to having the most motivated and best quality leaders.

You should assign a message to this category, if you think the message writer suggested in the message that he/she was considering whether one mechanism was better at selecting the best quality leader (for example, in terms of motivation or ability).

4. Reasons related to one's own chance of being selected as the leader.

You should assign a message to this category, if you think the message writer suggested in the message that he/she was considering how likely he/she would be selected as the leader if the mechanism was implemented.

\section{Reasons related to learning about one's own rank/performance in Experiment}

1.

You should assign a message to this category, if you think the message writer suggested in the message that he/she wanted to know where his/her performance in Experiment 1 stands vis-à-vis others.

6. No preference.

You should assign a message to this category, if you think the message writer suggested in the message that he/she did not have any preference over the two mechanisms. 


\section{Other - please specify.}

You should assign a message to this category, if it does not belong to any of the above categories. In this case, please also briefly explain your interpretation of the message.

While for coding the messages, please pay attention to the following:

1) You should code all messages independently. Please do not discuss with anyone else in this room how to code the messages.

2) Your job is to capture the underlying reasons for the decisions to compete for the leader position. Think of yourself as a "coding machine."

3) When you complete the coding, please go through the entire list of messages a second time to (i) review all your codes and revise them if needed for accuracy; (ii) make sure that you have coded every message.

Each participant is assigned the same set of messages to evaluate. The session ends after everyone finishes the coding task. At the end of the session, In addition to the show-up fee, each participant will be paid another $\$ 10$ for completing the coding task. 3 messages will be randomly chosen for payment. For each of these 3 messages, if your evaluation matches the most commonly chosen evaluation by the other participants in the session, you will be paid $\$ 5$ for that message. For example, for the chosen message, if most of the other participants in the session have picked Category 2, then you will receive $\$ 5$ if you have also picked Category 2. Similarly, if most of the other participants have picked both Category 5 and 7, then you will receive $\$ 5$ if you have also picked both Category 5 and 7. Hence, for payment, your answer should exactly match the most frequently given answer.

To evaluate the messages, you need to first understand the experiment. The instructions attached below are the instructions the participants read in Experiment I and II. Please read them carefully. After you finish reading the instructions, please complete the practice questions. 


\section{Appendix D. Team performance outcomes in the Leader and Group scenarios}

In the Group scenario, 19 out of the 21 selected leaders under both the Opt-in mechanism and the Opt-out mechanism were the best performer in Experiment 1. In the Leader scenario, this number is 20 out of 21 in the Opt-in and 20 out of 20 in the Opt-out mechanism. Similar to the results reported for the Third-party scenario, we do not find a significant difference in the leadership outcomes between the Opt-out and the Opt-in mechanisms in the Group scenario.

Table D.1. Leader Scenario

Mean
(s.e.) $\quad$ p-value

\begin{tabular}{|c|c|c|c|}
\hline \multirow{4}{*}{ Competitors' suggestions } & Opt-out & 16.03 & \multirow[b]{4}{*}{0.108} \\
\hline & (\# of obs.: 79) & $(1.41)$ & \\
\hline & Opt-in & 12.97 & \\
\hline & (\# of obs.: 78) & $(1.25)$ & \\
\hline \multirow{4}{*}{ Elected leader's message } & Opt-out & 15.55 & \\
\hline & (\# of obs.: 20) & $(2.59)$ & \\
\hline & Opt-in & 12.60 & \\
\hline & (\# of obs.: 20 ) & (2.38) & 0.332 \\
\hline \multirow{4}{*}{$\begin{array}{l}\text { Additional tasks completed } \\
\text { by non-leaders }\end{array}$} & Opt-out & 13.00 & \\
\hline & (\# of obs.: 60) & $(1.90)$ & \\
\hline & Opt-in & 9.37 & \\
\hline & (\# of obs.: 60) & $(1.71)$ & 0.083 \\
\hline \multirow{4}{*}{$\begin{array}{l}\text { Additional tasks completed } \\
\text { by the leader }\end{array}$} & Opt-out & 37.10 & \\
\hline & (\# of obs.: 20) & $(1.67)$ & \\
\hline & Opt-in & 37.10 & \\
\hline & (\# of obs.: 20 ) & (1.45) & 0.744 \\
\hline
\end{tabular}


Table D.2. Group Scenario

\begin{tabular}{|c|c|c|c|}
\hline & & $\begin{array}{l}\text { Mean } \\
\text { (s.e.) }\end{array}$ & $\mathrm{p}$-value \\
\hline \multirow{4}{*}{ Competitors' suggestions } & Opt-out & 28.53 & \\
\hline & (\# of obs.: 80 ) & $(1.28)$ & \\
\hline & Opt-in & 28.87 & \\
\hline & (\# of obs.: 66 ) & $(1.41)$ & 0.857 \\
\hline \multirow{4}{*}{ Elected leader's message } & Opt-out & 34.43 & \\
\hline & (\# of obs.: 21 ) & $(1.96)$ & \\
\hline & Opt-in & 30.14 & \\
\hline & (\# of obs.: 21) & (2.38) & 0.170 \\
\hline \multirow{4}{*}{$\begin{array}{l}\text { Additional tasks completed } \\
\text { by the non-leaders }\end{array}$} & Opt-out & 35.66 & \\
\hline & (\# of obs.: 63 ) & $(0.95)$ & \\
\hline & Opt-in & 35.63 & \\
\hline & (\# of obs.: 63 ) & $(1.15)$ & 0.716 \\
\hline \multirow{4}{*}{$\begin{array}{l}\text { Additional tasks completed } \\
\text { by the leader }\end{array}$} & Opt-out & 37.29 & \\
\hline & (\# of obs.: 21) & $(1.84)$ & \\
\hline & Opt-in & 35.48 & \\
\hline & (\# of obs.: 21) & (1.61) & 0.172 \\
\hline
\end{tabular}




\section{Appendix E. Content analysis of the survey responses}

For the content analysis in Part 2 of the second study, we apply the method introduced in Houser and Xiao (2011). The specific procedure is as follows. First, we read the explanations with two research assistants who were blind to the research questions and hypotheses relating to our project. Together we came up with seven categories, including fairness, freedom to choose, leader quality, and desire to increase own chance of being selected (see Table E.1(a) and the instructions in Appendix C for the complete list). A few of the participants answered that their choice was shaped by a desire to learn about their performance in Experiment 1. Such an answer suggests that the subject was confused, as the choice of the mechanism cannot possibly affect one's ability to learn their rank. We included this category for completeness, but we do not consider it in our analysis. It also turns out that the frequency of this classification is quite low (only 7 out of 80 in the Group scenario and 10 out of the 84 explanations in the Thirdparty scenario fall into this category).

We then recruited 29 subjects to code the responses (14 for the Group scenario session and 15 for the Third-party scenario session, none of whom participated in the first study or in Part 1 of the second study). The instructions contained explanations of the categories created. The subjects could pick multiple categories for the same response. They made their decisions based on the survey responses only, i.e., they did not know the corresponding mechanism choices (Opt-in, Opt-out, or indifference) of the subjects who participated in Part 1 . All of the subjects in a given session were assigned the same set of responses to code for a given leadership scenario (Group or Third-party). They were asked to code the responses independently. At the end of the session, we chose three survey responses randomly for payment. For each of these three responses, if a subject's categorization matched the most frequently chosen category by the others in the session, they were paid and extra $\$ 5$. Hence, they could potentially earn $\$ 15$ in addition to a show-up fee of $\$ 10$.

Table E.1(a) reports the overall distribution of the categories in the Group and Third-party scenarios. ${ }^{25}$ In both scenarios, very few responses were classified in the "other” category. This suggests that the other six categories provided in the instructions capture the content of the answers quite well. The Kappa statistics reported in the table

\footnotetext{
25 In the Third-party scenario, we exclude two answers that receive equal votes for two categories.
} 
show that the agreement of the coding varies from fair to substantial for all the categories except for "other", with most being in the moderate to substantial range.

We next examine for each category which selection mechanism dominates. For example, do those individuals who care about the fairness of the selection mechanism think the Opt-out mechanism is better than the Opt-in mechanism? Thus, for each category, we calculate how many subjects chose the Opt-in mechanism and how many chose the Opt-out mechanism. Table E.1(b) summarizes these results.

We focus on the first four categories. Within these four categories, fairness, quality of the leader, and my chance of winning are the most frequently used. The number of participants who mention freedom of choice in their explanation is quite low in both scenarios (5 in the Third-party and 8 in the Group scenario).

Amongst the participants who care about the fairness of the selection mechanism, more preferred the Opt-out mechanism over the Opt-in mechanism in the Third-party scenario (66.67\% vs. 33.33\%), while preferences were equally divided between the two mechanisms in the Group scenario. The choices of the participants who care about the quality of the leader are mixed. More of them prefer the Opt-in mechanism in the Third-party scenario (53.85\% vs. $46.15 \%)$ while the preferences are reversed in the Group scenario, with most subjects preferring the Opt-out mechanism (93.33\% vs. 6.67\%). The participants who chose a mechanism to maximize their chance of winning view the Opt-in mechanism as more preferable $(42.86 \%$ vs. $35.71 \%$ in the Third-party; $57.14 \%$ vs. $42.86 \%$ in the Group). Finally, in both the Third-party and Group scenarios, more subjects view the Opt-in mechanism as giving greater freedom of choice, even though the participants in fact have equal freedom of choice both mechanisms.

Due to the small sample size in each category, we do not have the power to provide statistical tests for the comparisons within each category in each scenario. If we pool across the two scenarios, we find that the Opt-out mechanism performs better in the "Quality of the leader" category, while the Opt-in mechanism performs better in the "Freedom of choice" category (Quality: 71\% vs. 29\%, Z-test, $\mathrm{p}<0.01$; Freedom: 23\% vs. $69 \%$, Z-test, $\mathrm{p}=0.02$ ). No significant differences are observed between the two mechanisms in the other two categories (Fairness: 61\% vs. 39\%, Z-test, $\mathrm{p}=0.14$; Chance of winning: $40 \%$ vs. $51 \%$, Z-test, $\mathrm{p}=0.34$ ).

In summary, the analysis of the survey across the two scenarios suggests that the Opt-out mechanism is not perceived as inferior to the Opt-in mechanism by those 
subjects who value fairness and those who would like to maximize their chance of winning. It is viewed as the better option for ensuring quality of leadership. The Optout mechanism may be less preferred by those who care about freedom of choice although less than $10 \%$ of subjects see this as an important factor in their decisions. Nevertheless, these results suggest that, in the implementation stage, more attention should be given to ensuring that employees do not see the Opt-out mechanism as reducing their freedom of choice.

Table E.1.

(a) Distribution of classification categories by treatments

\begin{tabular}{lll}
\hline \hline & $\begin{array}{l}\text { Third-party } \\
(\%)\end{array}$ & $\begin{array}{l}\text { Group } \\
(\%)\end{array}$ \\
\hline Freedom of choice & $5.95(0.39)$ & $10.00(0.47)$ \\
Fairness & $17.86(0.60)$ & $10.00(0.49)$ \\
Quality of the leader & $15.48(0.44)$ & $18.75(0.58)$ \\
My chance of winning & $16.67(0.49)$ & $26.25(0.66)$ \\
Learn my rank in Experiment I & $11.90(0.64)$ & $8.75(0.65)$ \\
No Preference & $27.38(0.66)$ & $20.00(0.77)$ \\
Other & $2.38(0.17)$ & $6.25(0.32)$ \\
Total \# of Obs. & $84 *$ & 80 \\
\hline
\end{tabular}

Note: The numbers in the parentheses are the kappa-statistic measure of inter-rater agreement. Cohen (1960) suggests that the kappa statistic should be interpreted as follows: values $\leq 0$ as indicating no agreement and $0.01-0.20$ as none to slight, $0.21-$ 0.40 as fair, $0.41-0.60$ as moderate, $0.61-0.80$ as substantial, and $0.81-1.00$ as almost perfect agreement.

* Two survey responses which received equal votes for two categories are not included in any of the classification categories. 
(b) Distribution of each classification category across the two mechanisms

\begin{tabular}{llllllllll}
\hline \hline & \multicolumn{3}{c}{ Third-party } & \multicolumn{3}{c}{ Group } & \multicolumn{3}{c}{ Pooled } \\
\cline { 2 - 10 } & $\begin{array}{l}\text { Total } \\
\text { \# }\end{array}$ & $\begin{array}{l}\text { Opt-in } \\
(\%)\end{array}$ & $\begin{array}{l}\text { Opt-out } \\
(\%)\end{array}$ & $\begin{array}{l}\text { Total } \\
\#\end{array}$ & $\begin{array}{l}\text { Opt-in } \\
(\%)\end{array}$ & $\begin{array}{l}\text { Opt-out } \\
(\%)\end{array}$ & $\begin{array}{l}\text { Total } \\
\#\end{array}$ & $\begin{array}{l}\text { Opt-in } \\
(\%)\end{array}$ & $\begin{array}{l}\text { Opt-out } \\
(\%)\end{array}$ \\
\hline Freedom of choice & 5 & 60.00 & 20.00 & 8 & 75.00 & 25.00 & 13 & 69.23 & 23.08 \\
Fairness & 15 & 33.33 & 66.67 & 8 & 50.00 & 50.00 & 23 & 39.13 & 60.87 \\
Quality of the leader & 13 & 53.85 & 46.15 & 15 & 6.67 & 93.33 & 28 & 28.57 & 71.43 \\
My chance of winning & 14 & 42.86 & 35.71 & 21 & 57.14 & 42.86 & 35 & 51.43 & 40 \\
Learn my rank in Experiment & 10 & 30.00 & 70.00 & 7 & 28.57 & 71.43 & 17 & 29.41 & 70.59 \\
No Preference & 23 & 21.74 & 8.69 & 16 & 6.25 & 18.75 & 39 & 15.38 & 12.82 \\
Other & 2 & 0.00 & 100.00 & 5 & 80.00 & 20.00 & 7 & 57.14 & 42.86 \\
Total Obs. \# & $84 *$ & 29 & 33 & 80 & 30 & 38 & 164 & 35.98 & 43.29 \\
\hline
\end{tabular}

* Two survey responses which received equal votes for two categories are not included in any of the categories. 